ARTICLE

\title{
Tailoring poplar lignin without yield penalty by combining a null and haploinsufficient CINNAMOYL-COA REDUCTASE2 allele
}

\author{
Barbara De Meester ${ }^{1,2}$, Barbara Madariaga Calderón ${ }^{1,2}$, Lisanne de Vries (10 1,2, Jacob Pollier (iD ${ }^{3}$, \\ Geert Goeminne $^{3}$, Jan Van Doorsselaere ${ }^{4}$, Mingjie Chen (1) ${ }^{5,6}$, John Ralph (10 ${ }^{5,6}$, Ruben Vanholme ${ }^{1,2,7} \&$ \\ Wout Boerjan (10) 1,2,7凶
}

Lignin causes lignocellulosic biomass recalcitrance to enzymatic hydrolysis. Engineered lowlignin plants have reduced recalcitrance but often exhibit yield penalties, offsetting their gains in fermentable sugar yield. Here, CRISPR/Cas9-generated CCR2 $\left(-/^{*}\right)$ line 12 poplars have one knockout CCR2 allele while the other contains a 3-bp deletion, resulting in a 1141115A-to$114 \mathrm{~T}$ conversion in the corresponding protein. Despite having $10 \%$ less lignin, CCR2 $\left(-/^{*}\right)$ line 12 grows normally. On a plant basis, the saccharification efficiency of CCR2 $\left(-/^{\star}\right)$ line 12 is increased by $25-41 \%$, depending on the pretreatment. Analysis of monoallelic CCR2 knockout lines shows that the reduced lignin amount in CCR2 $\left(-/^{\star}\right)$ line 12 is due to the combination of a null and the specific haploinsufficient CCR2 allele. Analysis of another CCR2 $\left(-/^{*}\right)$ line shows that depending on the specific CCR2 amino-acid change, lignin amount and growth can be affected to different extents. Our findings open up new possibilities for stably finetuning residual gene function in planta.

\footnotetext{
${ }^{1}$ Department of Plant Biotechnology and Bioinformatics, Ghent University, Technologiepark 71, 9052 Ghent, Belgium. ${ }^{2}$ VIB Center for Plant Systems Biology, Technologiepark 71, 9052 Ghent, Belgium. ${ }^{3}$ VIB Metabolomics Core, Technologiepark 71, 9052 Ghent, Belgium. ${ }^{4}$ Higher Institute for Nursing and Biotechnology, VIVES University College, Wilgenstraat 32, 8800 Roeselare, Belgium. ${ }^{5}$ Department of Biochemistry, University of Wisconsin-Madison, Madison, WI 53706, USA. ${ }^{6}$ US Department of Energy, Great Lakes Bioenergy Research Center, Wisconsin Energy Institute, Madison, WI 53726, USA.

${ }^{7}$ These authors jointly supervised this work: Ruben Vanholme, Wout Boerjan. ${ }^{{ }_{\text {email: }}}$ wout.boerjan@psb.vib-ugent.be
} 
$\mathrm{T}$ he lignin polymer provides strength and hydrophobicity to the plant cell wall and is generally derived from the monolignols coniferyl and sinapyl alcohol and low levels of p-coumaryl alcohol. Depending on the plant species, other monomers or derivatives may also contribute to the lignin polymer ${ }^{1}$. After polymerization in the cell wall, the monolignols produce guaiacyl $(\mathrm{G})$, syringyl $(\mathrm{S})$, and $p$-hydroxyphenyl $(\mathrm{H})$ units, respectively ${ }^{1}$.

Engineering plants to deposit less lignin is a promising strategy to enable improved biomass processability. However, hurdles need to be overcome for the development of low-lignin elite clones for forestry applications. One hurdle is to reduce lignin amount in a stable way. For example, RNA interference (RNAi) was frequently used to downregulate the expression of lignin biosynthesis genes in poplar ${ }^{2-5}$. However, this method often results in unstable downregulation of the targeted genes ${ }^{3-5}$. As an illustration, the red xylem phenotype caused by reductions in CINNAMOYL-CoA REDUCTASE (CCR) activity, appeared in patches on debarked CCR2-downregulated poplar stems, as a consequence of the unequal levels of gene silencing in red versus white regions ${ }^{3}$. Unequal gene silencing levels even appeared between individual clones of the same CCR2-downregulated line ${ }^{3}$. A second hurdle is to reduce lignin amount without affecting plant development and biomass yield. For example, the CCR2downregulated poplars with the highest levels of CCR2 downregulation had up to $24 \%$ less lignin and an up to $104 \%$ increased enzymatic cellulose-to-glucose conversion without pretreatment ${ }^{3}$. Unfortunately, similar to many other plants yielding higher cellulose-to-glucose conversion levels ${ }^{2,6-8}$, these CCR2-downregulated poplars suffered from a reduction of up to $51 \%$ in biomass, (entirely) offsetting their gains in fermentable sugar yield ${ }^{3}$. Hence, for applications, a method is desired to make plants with a stable and fine-tuned lignin amount to still achieve higher sugar yields in all replicates, but without affecting growth.

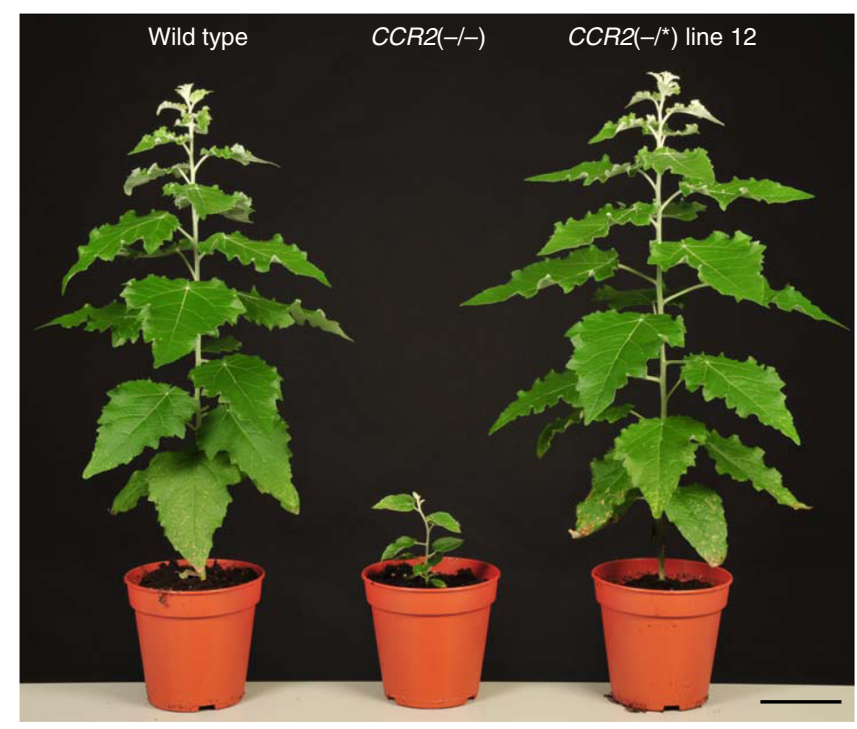

Fig. 1 Phenotype of poplar containing biallelic CCR2 mutations. Plants were grown for 11 weeks in the greenhouse. $\operatorname{CCR} 2(-/-)$ and $\operatorname{CCR} 2\left(-/^{\star}\right)$ line 12 poplars ( $P$. tremula $\times P$. alba) were generated via CRISPR/Cas 9 using gRNA1 (targeting the third exon of both CCR2 alleles). The status of the CCR2 alleles present in $P$. tremula $\times P$. alba is denoted between the parentheses; the first one represents that of the $P$. tremula allele, the second one that of the $P$. alba allele; - , knockout; ${ }^{\star}$, protein-modified. The plants shown are representative of twenty biologically independent samples for wild type and CCR2 $(-/-)$. One plant was available for $\operatorname{CCR} 2\left(-/^{*}\right)$ line 12. Scale bar $=10 \mathrm{~cm}$.
To evaluate the specific role of CCR2 in poplar, CCR2(-1-) null mutants are generated using CRISPR/Cas9. In addition to severely dwarfed CCR2(-/-) plants, a biallelically modified line has normal growth. Here, we show that this line, named CCR2 $\left(-/^{*}\right)$ line 12 , contains a knockout and a specific haploinsufficient CCR2 allele (114I115A-to-114T amino-acid change in the corresponding CCR2 protein sequence) that results in a uniformly distributed red xylem phenotype, a $10 \%$ reduction in lignin amount and a 25 to $41 \%$ increase in saccharification efficiency on a plant basis, depending on the applied pretreatment. Analysis of another CCR $2\left(-/^{*}\right)$ line shows that, whereas multiple amino-acid changes in CCR2 can result in lower lignin content (to different extents), they will not all allow normal growth. We propose that in planta screening for combinations of a knockout and a haploinsufficient allele is a promising strategy to fine-tune the desired level of residual gene function.

\section{Results}

CCR2(-/*) line 12 grows normally while having red xylem. To evaluate the effect of fully knocking out CCR2 on the phenotype of poplar, we generated 21 biallelically edited CCR2 mutants in Populus tremula $\times$ P. alba by CRISPR/Cas9 using a gRNA (gRNA1) targeting the third exon of the CCR2 gene (Supplementary Fig. 1a). The twenty lines that contained biallelic frameshift mutations in CCR2, CCR2(-/-) lines, were all severely dwarfed (Fig. 1; Supplementary Fig. 1b). Interestingly, one biallelic mutant line did not display observable growth perturbations (Fig. 1). CCR2(-/*) line 12 had a frameshift mutation (1-bp insertion) in the P. tremula CCR2 allele, and a deletion of 3 bp in the P. alba CCR2 allele, which resulted into a substitution of Ile114 and Ala115 for a Thr114 in the corresponding P. alba CCR2 protein sequence (Supplementary Figs. $1 \mathrm{~b}$ and 2). The amino-acid change occurred in a 4 of the CCR2 protein, but not in the active site, NAPD-binding domain, or substrate-binding pocket residues ${ }^{9-11}$.

To evaluate the growth and xylem phenotypes of CCR2(-1*) line 12 , wild type, and $\operatorname{CCR} 2\left(-/^{*}\right)$ line 12 were clonally propagated to generate multiple biological replicates. The replicates were grown in the greenhouse for a period of 20 weeks. Plant height was followed weekly, and by the end of the growth period, the trees were harvested, and biomass parameters were determined. The stem height of CCR2 $\left(-/^{*}\right)$ line 12 was equal to that of the wild type during the entire growth period (Fig. 2a, Supplementary Table 1$)$. At harvest time, the CCR $2\left(-/^{*}\right)$ line 12 plants were morphologically indistinguishable from the wild type (Fig. 2b), and no differences in either stem diameter or fresh and dry stem weight were observed (Table 1).

After debarking the harvested stems, the coloration of the xylem could be judged; whereas wild-type xylem had a white-tobeige color, CCR2 $\left(-/^{*}\right)$ line 12 xylem displayed a uniform pinkto-red coloration (Fig. 2c). This xylem coloration is often observed in lignin-modified plants $3,4,12,13$ and suggested a modified lignin in $\operatorname{CCR} 2\left(-/^{*}\right)$ line 12 as compared to the wild type.

To examine the morphology of the xylem cells in the stem, cross-sections of wild type, CCR2 $\left(-/^{*}\right)$ line 12 , and CCR2(-/-) were observed via light microscopy after Wiesner and Mäule staining, and via fluorescence microscopy (Fig. 3). Wild-type and CCR2 $\left(-/^{*}\right)$ line 12 stem sections were morphologically indistinguishable. They both had fiber and vessel cells with lignified cell walls, and the vessel cells were open. By contrast, CCR2(-/-) stems showed an overall reduction in lignin deposition in the cell walls of both fiber and vessel cells, and the vessel cells had an irregular shape. 
a

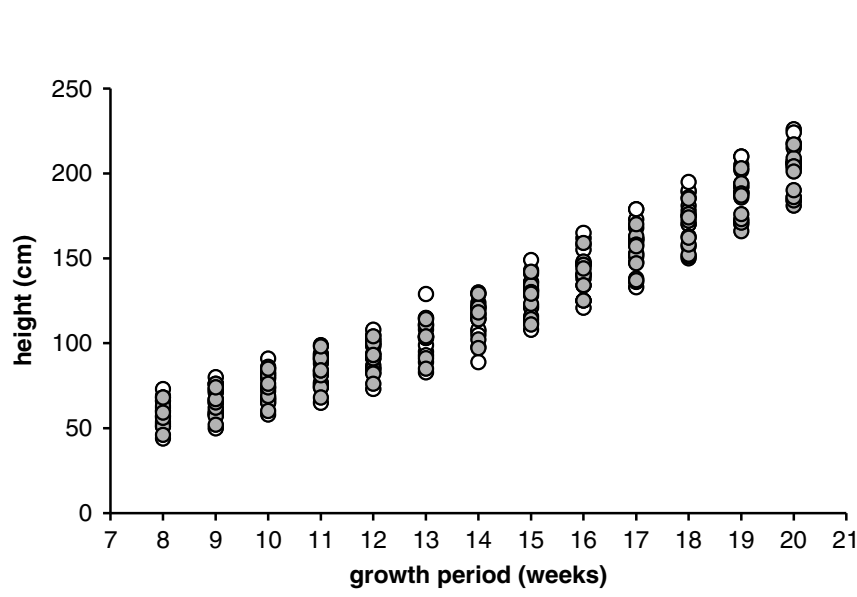

b

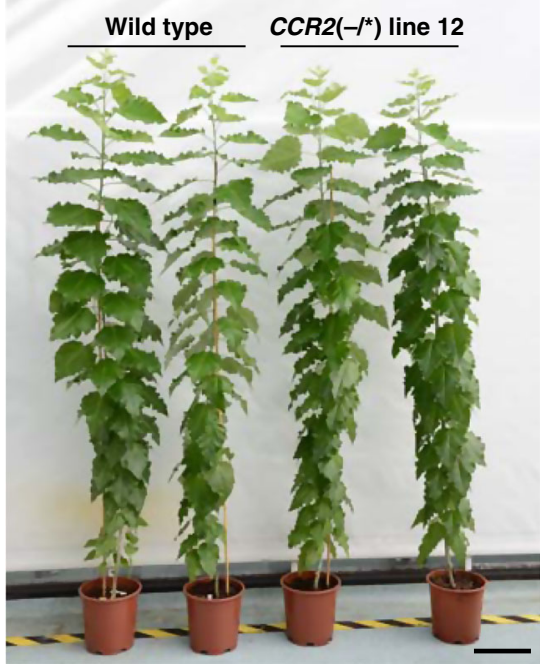

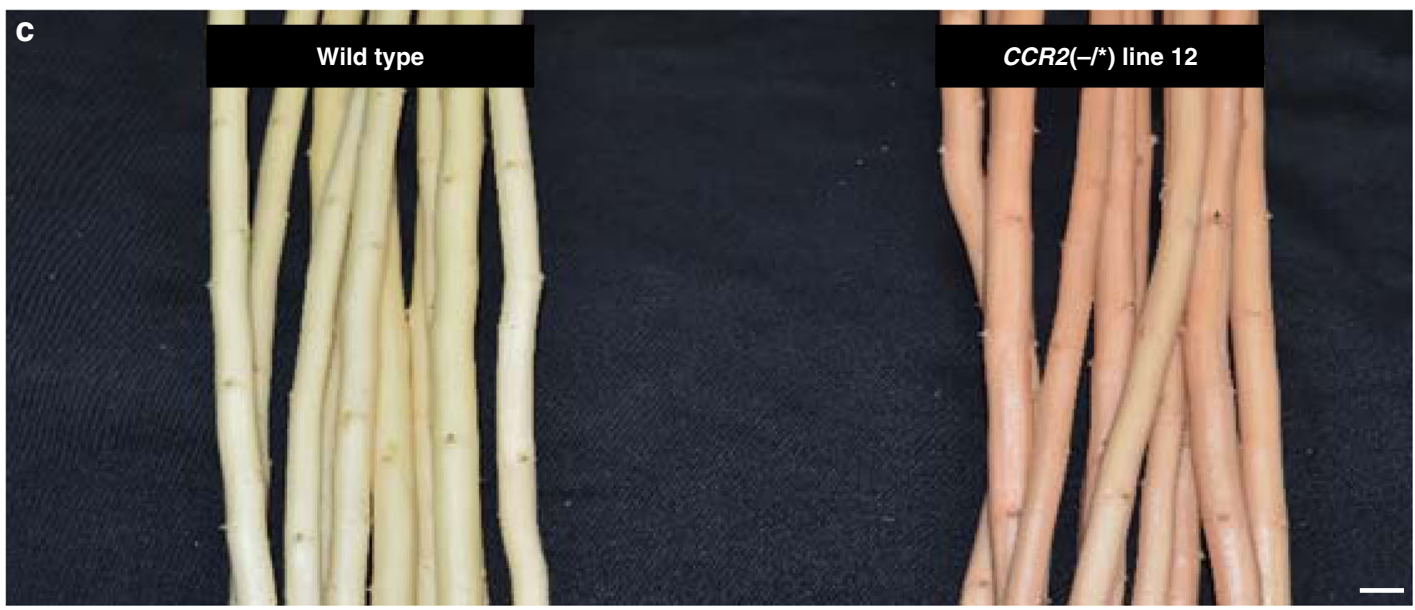

Fig. 2 Phenotype of $\operatorname{CCR2}\left(-/^{\star}\right)$ line 12 poplar. Plants were grown for 20 weeks in the greenhouse. a Growth curve of wild type and CCR2( $\left./^{\star}\right)$ line 12 . No significant differences in height were found between the wild type (individual values shown in white dots) and CCR2( $\left./{ }^{\star}\right)$ line 12 (individual values shown in gray dots) at the 0.01 significance level (two-tailed Student's $t$-test). For mean values and exact $P$ values, see Supplementary Table 1 . b Phenotype of representative wild type and $C C R 2\left(-/^{\star}\right)$ line 12 after growing for 20 weeks in the greenhouse. Scale bar $=20 \mathrm{~cm}$. c Phenotype of debarked wild-type and $\operatorname{CCR} 2\left(-/^{\star}\right)$ line 12 stems grown in the greenhouse for 20 weeks. CCR2 $\left(-/^{\star}\right)$ line 12 stems display the red xylem phenotype. Scale bar $=10$ mm. Wild type, $n=10$ biologically independent samples; CCR2 $\left(-/^{\star}\right)$ line $12, n=11$ biologically independent samples. The source data underlying (a) are provided as a Source data file.

\begin{abstract}
Altered lignin in $\operatorname{CCR2}\left(-/^{*}\right)$ line 12. To evaluate the lignocellulosic biomass composition of CCR $2\left(-/^{*}\right)$ line 12 stems, the cell wall residue (CWR), the cellulose content, and the lignin content and composition of dried debarked stem material were determined (Table 1). CWR was prepared by applying a sequential extraction to remove soluble compounds from the stems. The fraction of CWR (as \% of the dry weight) of CCR $2\left(-/^{*}\right)$ line 12 did not differ from that of the wild type. The cellulose content of the prepared CWRs was analyzed via the spectrophotometric Updegraff assay which showed that the crystalline cellulose content of CCR2 $\left(-/^{*}\right)$ line 12 did not differ significantly from that of the wild type. The combined amount of matrix polysaccharides and amorphous cellulose-determined as the mass loss upon trifluoroacetic acid treatment-in the CWRs of $\operatorname{CCR} 2\left(-/^{*}\right)$ line 12 was increased by about $10 \%$ when compared to that of the wild type. Next, the fraction of lignin in the prepared CWRs was determined via the Klason and the acetyl bromide methods. Both methods showed that the total lignin amount of CCR $2\left(-/^{*}\right)$ line 12 was decreased by about $10 \%$ when compared to that of the wild type.
\end{abstract}

Lignin composition in the CWRs was evaluated via thioacidolysis, an analytical method that quantifies lignin units solely linked by $\beta-O-4$ bonds (Table 1$)$. CCR2 $\left(-/^{*}\right)$ line 12 lignins showed a trend towards releasing more monomers $(\mathrm{H}+\mathrm{G}+\mathrm{S})$ when compared to wild-type lignins $(P=0.092)$, indicative for a slightly higher frequency of $\beta-O-4$ interunit bonds. In the wild type, $\mathrm{H}$ monomers constituted $1.6 \%$ of the total identified thioacidolysis-released units. In CCR2 $\left(-/^{*}\right)$ line 12 , the fraction of thioacidolysis-released $\mathrm{H}$ units was only $0.3 \%$. The $\mathrm{S} / \mathrm{G}$ ratio based on thioacidolysis-released monomers was equal for the wild type and $\operatorname{CCR} 2\left(-/^{*}\right)$ line 12 . Incorporation of ferulic acid (FA), which is a known minor constituent of lignin, results in the release of three different units after thioacidolysis: $\beta-O-4-\mathrm{FA}-\mathrm{I}$ and $\beta-O-4-\mathrm{FA}-\mathrm{II}$ are derived from ferulic acid (or ferulate ester) starting units coupled via their $O-4$ position in $\beta-O-4$ interunit bonds, whereas bis- $\beta-O-4-\mathrm{FA}$ is derived from ferulic acid that has undergone a $\beta-O-4$ coupling twice at its $\beta$-position ${ }^{14}$. In agreement with previously reported results for plants deficient in $\mathrm{CCR}^{3,5,14-16}$, the relative abundance of all three 
Table 1 Biomass and cell wall composition of $\operatorname{CCR2}\left(-/^{\star}\right)$ line 12 stems.

\begin{tabular}{|c|c|c|c|}
\hline & Wild type & $\begin{array}{l}\operatorname{CCR2}\left(-/^{\star}\right) \\
\text { line } 12\end{array}$ & $P$ value \\
\hline Fresh weight with bark (g) & $87.6 \pm 23.9$ & $87.0 \pm 19.4$ & 0.956 \\
\hline Fresh weight debarked $(\mathrm{g})$ & $57.4 \pm 15.0$ & $57.0 \pm 13.1$ & 0.940 \\
\hline Dry weight debarked $(\mathrm{g})$ & $18.8 \pm 5.6$ & $17.6 \pm 4.6$ & 0.582 \\
\hline Height $(\mathrm{cm})$ & $207.4 \pm 14.2$ & $198.2 \pm 11.9$ & 0.123 \\
\hline Diameter (mm) & $11.4 \pm 1.0$ & $11.0 \pm 0.8$ & 0.427 \\
\hline CWR (\% dry weight) & $87.8 \pm 0.7$ & $87.4 \pm 0.7$ & 0.156 \\
\hline Cellulose (\% CWR) & $39.6 \pm 3.8$ & $39.5 \pm 3.9$ & 0.976 \\
\hline $\begin{array}{l}\text { Matrix } \\
\text { polysaccharides (\%CWR) }\end{array}$ & $37.8 \pm 1.8$ & $41.9 \pm 3.1^{\star \star}$ & 0.002 \\
\hline $\begin{array}{l}\text { Total Klason lignin } \\
(\% \text { CWR })\end{array}$ & $31.1 \pm 1.5$ & $27.8 \pm 0.9^{\star \star}$ & $5.8 \times 10^{-6}$ \\
\hline $\begin{array}{l}\text { Acid-insoluble Klason } \\
\text { lignin (\%CWR) }\end{array}$ & $29.4 \pm 1.5$ & $26.0 \pm 0.9^{\star \star}$ & $3.4 \times 10^{-6}$ \\
\hline $\begin{array}{l}\text { Acid-soluble Klason } \\
\text { lignin (\%CWR) }\end{array}$ & $1.69 \pm 0.10$ & $\begin{array}{l}1.82 \pm \\
0.10^{\star \star}\end{array}$ & 0.008 \\
\hline $\begin{array}{l}\text { Acetyl bromide lignin } \\
\text { (\%CWR) }\end{array}$ & $17.1 \pm 1.3$ & $15.4 \pm 0.7^{\star \star}$ & 0.004 \\
\hline \multicolumn{4}{|c|}{ Thioacidolysis-released monomers } \\
\hline $\mathrm{H}+\mathrm{G}+\mathrm{S}$ & $15.9 \pm 0.9$ & $15.4 \pm 0.5$ & 0.092 \\
\hline$\% \mathrm{H}$ & $1.6 \pm 0.2$ & $0.3 \pm 0.1^{\star \star}$ & $5.0 \times 10^{-9}$ \\
\hline$\% \mathrm{~S}$ & $56.1 \pm 0.5$ & $56.7 \pm 0.8$ & 0.087 \\
\hline$\% G$ & $42.3 \pm 0.5$ & $43.0 \pm 0.8^{\star}$ & 0.020 \\
\hline$S / G$ & $1.33 \pm 0.03$ & $1.32 \pm 0.04$ & 0.521 \\
\hline \multirow[t]{2}{*}{$\% \beta-O-4-F A-1$} & $0.013 \pm$ & $0.073 \pm$ & $1.6 \times 10^{-7}$ \\
\hline & 0.003 & $0.016^{\star \star}$ & \\
\hline \multirow[t]{2}{*}{$\% \beta-O-4-F A-I I$} & $0.006 \pm$ & $0.040 \pm$ & $1.0 \times 10^{-9}$ \\
\hline & 0.001 & $0.005^{\star \star}$ & \\
\hline \multirow[t]{2}{*}{$\%$ bis- $\beta-O-4-F A$} & $0.107 \pm$ & $0.818 \pm$ & $6.2 \times 10^{-7}$ \\
\hline & 0.040 & $0.223^{\star \star}$ & \\
\hline$\% G$-aldehydes & $1.0 \pm 0.2$ & $1.2 \pm 0.1$ & 0.097 \\
\hline \multicolumn{4}{|l|}{ NMR-derived aromatic units } \\
\hline$\% \mathrm{H}$ & $0.54 \pm 0.22$ & $0.27 \pm 0.06$ & 0.113 \\
\hline$\% \mathrm{~S}$ & $59.7 \pm 0.7$ & $56.2 \pm 1.4^{\star}$ & 0.021 \\
\hline$\% \mathrm{G}$ & $39.8 \pm 0.6$ & $43.5 \pm 1.5^{\star}$ & 0.016 \\
\hline$S / G$ & $1.50 \pm 0.04$ & $1.29 \pm 0.08^{\star}$ & 0.015 \\
\hline$\% p B A$ & $6.3 \pm 0.4$ & $11.0 \pm 0.6^{\star \star}$ & $3.3 \times 10^{-4}$ \\
\hline$\% F M$ & 0.0 & $0.2^{\star \star \star \star}$ & \\
\hline \multicolumn{4}{|l|}{$\begin{array}{l}\text { NMR-derived interunit } \\
\text { linkages }\end{array}$} \\
\hline$\% \beta$-Aryl ether $(A)$ & $83.7 \pm 0.4$ & $86.5 \pm 1.3^{\star}$ & 0.026 \\
\hline \%Phenylcoumaran (B) & $6.0 \pm 0.3$ & $5.9 \pm 1.1$ & 0.826 \\
\hline \%Resinol (C) & $10.2 \pm 0.4$ & $7.6 \pm 0.2^{\star \star}$ & $6.2 \times 10^{-4}$ \\
\hline
\end{tabular}

Plants were grown for 20 weeks in the greenhouse. Stem diameter was determined $3 \mathrm{~cm}$ above soil level. At the time of harvest, the height, fresh weight (without leaves; with or without bark), and diameter of the stem were measured. After drying the debarked stems for 2 weeks, the dry weight was determined. Cell wall residue (CWR) was determined after sequential extraction of dry debarked stem material. Crystalline cellulose content was determined by the Updegraff method and the mass loss during TFA extraction was used as an estimate of the amount of matrix polysaccharides. Lignin content was determined by the Klason and acetyl bromide methods. Lignin composition was determined by 2D HSQC NMR and by thioacidolysis. The sum of $\mathrm{H}, \mathrm{G}$, and $\mathrm{S}$ is expressed in $\mu \mathrm{mol}$ per $\mathrm{g}$ Klason lignin. $\% \mathrm{H}+\% \mathrm{G}+\% \mathrm{~S}=100$; other units are expressed versus $\mathrm{H}+\mathrm{G}+\mathrm{S}$. $p \mathrm{BA}$ : $p$-hydroxybenzoate; FM: ferulic acid marker (see

Supplementary Fig. 3). Lignin interunit types $(A-C)$, from uncorrected volume-integrals only, are expressed on an $A+B+C=100 \%$ basis. The data represent means \pm standard deviation ${ }^{\star *} P<$ $0.01,{ }^{\star} P<0.05$, two-tailed Student's $t$-test. The exact $P$ value is shown in the table. For NMR, wild type and CCR2 $\left(-/^{\star}\right)$ line $12, n=3$ biologically independent samples. For all other analysis, wild type, $n=10$ biologically independent samples and $\operatorname{CCR} 2\left(-/^{*}\right)$ line $12, n=11$ biologically independent samples. Source data are provided as a Source data file.

thioacidolysis-released ferulic acid units was increased in CCR $2\left(-/^{*}\right)$ line 12 when compared to the wild type.

The lignin composition was also analyzed via two-dimensional ${ }^{1} \mathrm{H}-{ }^{13} \mathrm{C}$ heteronuclear single-quantum coherence (2D HSQC) nuclear magnetic resonance (NMR) on ball-milled whole-cellwall material prepared from the stem (Table 1, Supplementary Fig. 3). By analyzing the aromatic regions of the 2D HSQC spectra, it is possible to profile differences in lignin monomeric composition irrespective of the interunit linkage distribution. Using NMR, the estimated relative frequency of $\mathrm{H}$ units showed no significant differences between wild type and CCR2 $\left(-/^{*}\right)$ line 12. However, the determination of $H$ units via NMR is neither sensitive nor accurate because the peaks used for their estimation are contaminated by those from phenylalanine ${ }^{17}$. In contrast to the results obtained by thioacidolysis, the $S / G$ ratio was decreased by $14 \%$ in $\operatorname{CCR} 2\left(-/^{*}\right)$ line 12 when compared to the wild type. Similar to the results obtained from thioacidolysis, the ferulic acid marker peak was clearly detected in spectra from $\operatorname{CCR} 2\left(-/^{*}\right)$ line 12 wood, while being absent in spectra from the wild type. In addition, the NMR data enabled the relative measurement of $p$ hydroxybenzoates that acylate the sidechain $\gamma-\mathrm{OH}$ of $\mathrm{G}$ and, predominantly, $S$ units in poplar. The relative frequency of these moieties was increased by $75 \%$ in CCR2 $\left(-/^{*}\right)$ line 12 when compared to the wild type. This observation is in line with the fact that the biosynthesis of $p$-hydroxybenzoates, in contrast to that of $\mathrm{H}, \mathrm{G}$, and $\mathrm{S}$ units, is independent of CCR2 activity. The interunit linkage-type distributions were also deduced from the NMR spectra. The lignin of CCR $2\left(-/^{*}\right)$ line 12 showed an increase in the relative proportion of $\beta$-aryl ether $(\beta-O-4)$ units, at the expense of resinol $(\beta-\beta)$ units. The fraction of phenylcoumarans $(\beta-5)$ did not differ between CCR2 $\left(-/^{*}\right)$ line 12 and the wild type.

Finally, analysis by gel-permeation chromatography (GPC) showed that the molecular weight of CCR2 $\left(-/^{*}\right)$ line 12 lignin tended to be lower than that of wild-type lignin (Supplementary Table 2).

Together, these data show that, although the growth of the CCR2 $\left(-/^{*}\right)$ line 12 trees is similar to that of wild-type trees, their wood composition still reflects a deficiency in CCR2.

Increased saccharification efficiency in $\operatorname{CCR} 2\left(-/^{*}\right)$ line 12. Because lignin amount, composition, and polymerization degree greatly influence saccharification yield, we further investigated the saccharification potential of CCR $2\left(-/^{*}\right)$ line 12 under conditions of limited saccharification. The cellulose-to-glucose conversion was calculated based on the amount of glucose released upon saccharification of dried debarked stem material after either acidic $\left(1 \mathrm{M} \mathrm{HCl}, 80^{\circ} \mathrm{C}, 2 \mathrm{~h}\right)$, alkaline $\left(62.5 \mathrm{mM} \mathrm{NaOH}, 90^{\circ} \mathrm{C}, 3 \mathrm{~h}\right)$, or no pretreatment (Supplementary Table 3 ) and the original cellulose content that was measured for each sample (Table 1). In all three cases, cellulose-to-glucose conversion of biomass from CCR2 $\left(-/^{*}\right)$ line 12 was significantly higher than that of the wild type (Fig. 4); the cellulose-to-glucose conversion of the non-pretreated samples increased from $23.9 \%$ in the wild type to $32.4 \%$ in CCR2 $\left(-/^{*}\right)$ line 12 (i.e., a relative increase of $36 \%$ ), after acidic pretreatment from 30.3 to $46.4 \%$ (i.e., a relative increase of $53 \%$ ), and after alkaline pretreatment from 70.9 to $95.9 \%$ (i.e., a relative increase of 35\%).

In many plant species, including Arabidopsis, tobacco, and poplar, lowering CCR activity leads to a substantial yield penalty $3,5,18,19$. As CCR2(-/*) line 12 had a biomass yield and cellulose amount that was comparable to that of the wild type, the saccharification yield expressed on a per plant basis was also increased in CCR2 $\left(-/^{*}\right)$ line 12 under the used pretreatment conditions (Supplementary Table 3); using no pretreatment, acidic pretreatment, and alkaline pretreatment, the glucose yield per plant of CCR2 $\left(-/^{*}\right)$ line 12 was increased by $25.3 \%, 41.3 \%$, and $24.9 \%$, respectively.

Haplosufficient wild-type $P$. tremula $\times P$. alba $C C R 2$ alleles. In CCR2 $\left(-/^{*}\right)$ line 12 , the $P$. tremula CCR2 allele contained a frameshift mutation, thereby fully knocking out this allele. However, the effect of the 114I115A-to-114T amino-acid change 


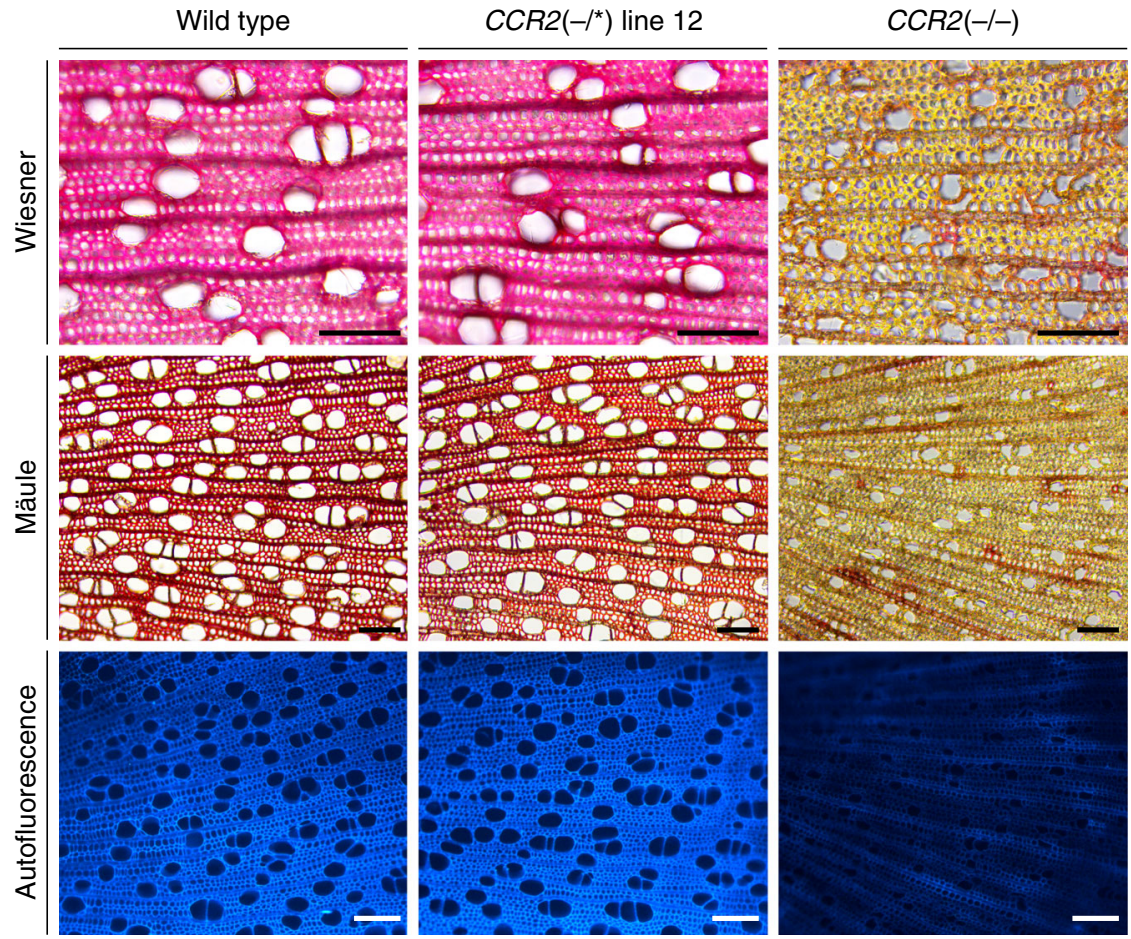

Fig. 3 Xylem morphology in stems of CCR2( $\left./^{\star}\right)$ line 12 and CCR2( $-\boldsymbol{J}_{-}$) poplars. Plants were grown for 20 weeks in the greenhouse. Lignin was visualized using Mäule and Wiesner staining and via lignin autofluorescence $\left(\lambda_{\mathrm{ex}}=365 \mathrm{~nm}, \lambda_{\mathrm{em}}=420-470 \mathrm{~nm}\right)$. Pictures were taken of the xylem tissue, with the pith localized to the left and the epidermis to the right. Images show representative pictures from five sections per sample and 3 biologically independent samples per line. Scale bar $=100 \mu \mathrm{m}$.

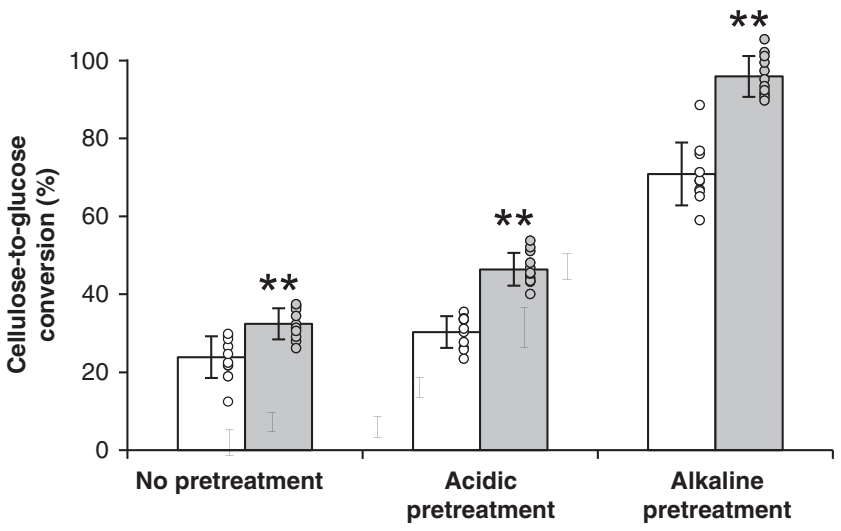

Fig. 4 Saccharification assays of CCR2( $\left.-/^{\star}\right)$ line 12 stems. Plants were grown for 20 weeks in the greenhouse. Cellulose-to-glucose conversion efficiencies of wild type and CCR2 $\left(-/^{*}\right)$ line 12 were calculated based on the quantified amounts of cellulose and the amount of released glucose after $72 \mathrm{~h}$ of saccharification following no pretreatment, acidic pretreatment $(1 \mathrm{M} \mathrm{HCl})$, or alkaline pretreatment $(62.5 \mathrm{mM} \mathrm{NaOH})$ (Supplementary Table 3, Table 1). Individual values (dots) and means (bars) of 10 biologically independent samples for wild type (white bars) and eleven biologically independent samples for $\operatorname{CCR} 2\left(-/^{\star}\right)$ line 12 (gray bars). ${ }^{\star \star} P<0.01$ (two-tailed Student's $t$-test); $P=5.1 \times 10^{-4}, 3.4 \times 10^{-8}$, and $6.6 \times 10^{-8}$ in the case of no pretreatment, acid pretreatment, and alkaline pretreatment, respectively (see also Supplementary Table 3). Error bars indicate standard deviation. Source data are provided as a Source data file.

in the protein encoded by the mutant $P$. alba CCR2 allele on total CCR activity was not known. Either the 114I115A-to-114T amino acid change in the $P$. alba CCR2 protein did not have any effect on the CCR2 activity, in which case the red xylem phenotype and the reduced lignin amount of CCR $2\left(-/^{*}\right)$ line 12 can be explained by the haploinsufficiency of the wild-type $P$. alba CCR2 allele. In this case, the CCR activity of the protein encoded solely by the wild-type $P$. alba CCR2 allele does not suffice to secure normal lignin biosynthesis. Alternatively, the wild-type P. alba CCR2 allele is haplosufficient, and the amino-acid change in the mutant $P$. alba CCR2 protein encoded by CCR2 $\left(-/^{*}\right)$ line 12 reduces CCR2 activity resulting in the reduced lignin amount and the consequent red xylem phenotype.

To test whether a single CCR2 allele, be it that encoded by the $P$. tremula or that by the $P$. alba genome, is sufficient to secure wild-type lignin amount, monoallelic null mutants in CCR2 were generated by CRISPR/Cas9. gRNA2 and gRNA3 were used, targetting the fourth exon of the CCR2 P. alba and P. tremula allele, respectively (Supplementary Fig. 4a, 5a). Six lines contained monoallelic frameshift mutations in P. alba CCR2 $($ CCR2 $(+/-)$; Supplementary Fig. 4b), while six out of eight lines in which the $P$. tremula CCR2 allele was targeted contained monoallelic frameshift mutations in P. tremula CCR2 (CCR2(-/+); Supplementary Fig. 5b). The other two lines contained biallelic mutations in CCR2. CCR2(-/-) line 202 contained biallelic frameshift mutations in CCR2 and was severely dwarfed, in agreement with the biallelic frameshift mutants generated previously using gRNA1 (Supplementary Fig. 5b, Figs. 1 and 5). CCR2 $\left(-/^{*}\right)$ line 206 contained a frameshift mutation (5-bp deletion) in the P. tremula CCR2 allele, and a deletion of $3 \mathrm{bp}$ in the P. alba CCR2 allele (Supplementary Fig. 5b) and will be discussed further below.

The twelve individual plants containing monoallelic frameshift mutations in CCR2 (as shown in Supplementary Figs. 4b and $5 b)$ were grown along with wild type and CCR2 $\left(-/^{*}\right)$ line 12 in the greenhouse. After a growth period of 11 weeks, both the CCR $2(+/-)$ and CCR2 $(-/+)$ monoallelic knock-outs and CCR2 $\left(-/^{*}\right)$ line 12 plants were equal to the wild type in stem height and diameter, as well as fresh and dry weight (Table 2, 


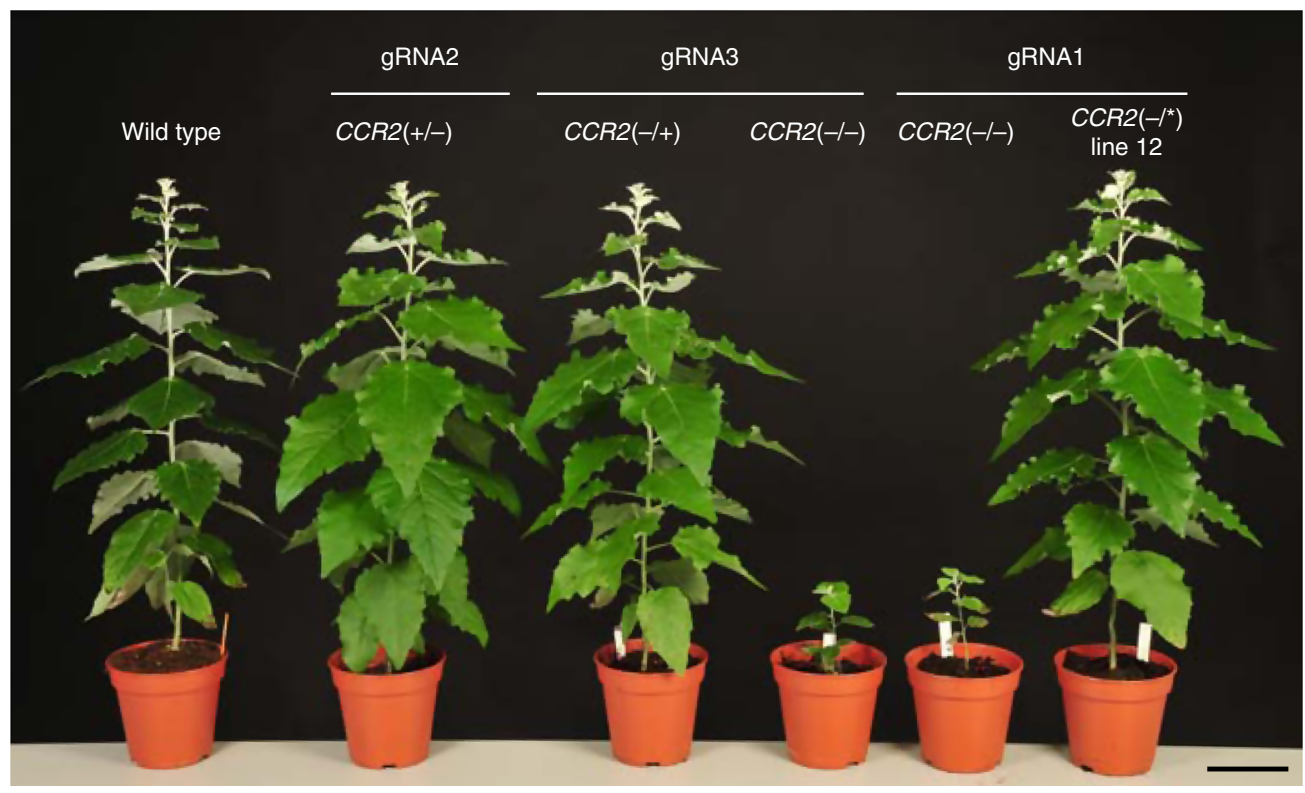

Fig. 5 Phenotype of poplar containing mono- and biallelic CCR2 mutations. Plants were grown for 11 weeks in the greenhouse. CCR2 $(+/-)$ generated via CRISPR/Cas9 using gRNA2, CCR2 $(-/+)$ and CCR2 $(-/-)$ generated via CRISPR/Cas9 using gRNA3, and CCR2( $/ /-)$ and CCR2 $\left(-/{ }^{*}\right)$ line 12 generated via CRISPR/Cas 9 using gRNA1. gRNA1 targets the third exon of both CCR2 alleles whereas gRNA2 and gRNA3 target the fourth exon of the $P$. alba or $P$. tremula $C C R 2$ allele, respectively. The status of the CCR2 alleles present in $P$. tremula $\times P$. alba is denoted between the parentheses; the first one represents that of the $P$. tremula allele, the second one that of the $P$. alba allele; + , wild type; - , knockout; ${ }^{*}$, protein-modified. The plants shown are representative for seven biologically independent samples for wild type, CCR2 $(+/-), \operatorname{CCR} 2(-/+), \operatorname{CCR} 2(-/-)$ (gRNA1), and CCR2 $\left(-/^{*}\right)$ line 12 . One plant was available for CCR2 $(-/-)$ (gRNA3). Scale bar $=10 \mathrm{~cm}$.

Table 2 Biomass and cell wall composition of $\operatorname{CCR2}(-/+), \operatorname{CCR2}(+/-)$, and $\operatorname{CCR2}\left(-/^{\star}\right)$ line 12 stems.

\begin{tabular}{|c|c|c|c|c|}
\hline & Wild type & $\operatorname{CCR2}(-/+)$ & $\operatorname{CCR2}(+/-)$ & $\operatorname{CCR2}\left(-/^{\star}\right)$ line 12 \\
\hline Fresh weight $(\mathrm{g})$ & $4.9 \pm 0.5$ & $3.4 \pm 2.6(0.276)$ & $5.8 \pm 1.6(0.355)$ & $4.0 \pm 1.3(0.640)$ \\
\hline Dry weight $(g)$ & $1.1 \pm 0.2$ & $0.8 \pm 0.6(0.389)$ & $1.4 \pm 0.5(0.530)$ & $0.9 \pm 0.3(0.528)$ \\
\hline Height $(\mathrm{cm})$ & $59.3 \pm 2.7$ & $51.8 \pm 12.6(0.237)$ & $64.2 \pm 7.5(0.564)$ & $53.0 \pm 4.2(0.331)$ \\
\hline Diameter (mm) & $6.0 \pm 0.0$ & $4.8 \pm 1.2(0.052)$ & $6.4 \pm 0.8(0.674)$ & $5.5 \pm 0.6(0.521)$ \\
\hline CWR (\% dry weight) & $70.6 \pm 4.3$ & $75.6 \pm 2.0(0.174)$ & $73.3 \pm 2.6(0.628)$ & $74.4 \pm 7.5(0.334)$ \\
\hline $\begin{array}{l}\text { Acetyl bromide lignin amount } \\
(\% \text { CWR) }\end{array}$ & $16.5 \pm 1.2$ & $16.2 \pm 0.7(0.888)$ & $16.7 \pm 0.7(0.936)$ & $14.0 \pm 0.8^{\star \star}(<0.0001)$ \\
\hline \multicolumn{5}{|l|}{ Thioacidolysis-released monomers } \\
\hline $\mathrm{H}+\mathrm{G}+\mathrm{S}$ & $34.1 \pm 1.7$ & $35.2 \pm 2.6(0.896)$ & $33.9 \pm 3.9(0.999)$ & $34.0 \pm 4.6(0.999)$ \\
\hline$\% \mathrm{H}$ & $0.9 \pm 0.3$ & $0.5 \pm 0.1(0.050)$ & $0.6 \pm 0.3(0.053)$ & $0.3 \pm 0.1^{\star \star}(<0.0001)$ \\
\hline$\% \mathrm{~S}$ & $56.1 \pm 0.9$ & $55.7 \pm 0.6(0.806)$ & $55.7 \pm 1.0(0.782)$ & $55.0 \pm 1.0(0.080)$ \\
\hline$\% \mathrm{G}$ & $41.9 \pm 1.2$ & $42.7 \pm 0.9(0.421)$ & $42.8 \pm 0.9(0.311)$ & $43.3 \pm 1.4(0.071)$ \\
\hline$S / G$ & $1.34 \pm 0.06$ & $1.31 \pm 0.04(0.507)$ & $1.30 \pm 0.05(0.417)$ & $1.27 \pm 0.06(0.063)$ \\
\hline$\% \beta-O-4-F A-I$ & $0.010 \pm 0.001$ & $0.013 \pm 0.001(0.994)$ & $0.013 \pm 0.004(0.992)$ & $0.086 \pm 0.037^{\star \star}(<0.0001)$ \\
\hline$\% \beta-O-4-F A-I I$ & $0.005 \pm 0.001$ & $0.005 \pm 0.001(0.943)$ & $0.004 \pm 0.002(0.966)$ & $0.033 \pm 0.004^{\star \star}(<0.0001)$ \\
\hline$\%$ bis- $\beta-0-4-\mathrm{FA}$ & $0.064 \pm 0.021$ & $0.058 \pm 0.018(0.999)$ & $0.045 \pm 0.033(0.992)$ & $0.365 \pm 0.288^{\star \star}(0.00354)$ \\
\hline$\% G$-aldehydes & $1.1 \pm 0.2$ & $0.9 \pm 0.4(0.898)$ & $0.8 \pm 0.5(0.379)$ & $0.9 \pm 0.4(0.919)$ \\
\hline
\end{tabular}

Plants were grown for 11 weeks in the greenhouse. Stem diameter was determined $3 \mathrm{~cm}$ above soil level. At the time of harvest, the height, fresh weight (without bark and leaves), and diameter of the stem were measured. After drying the debarked stems for 5 days, the dry weight was determined. Cell wall residue (CWR) was determined after sequential extraction of dry debarked stem material. Lignin content was determined via the acetyl bromide method. Lignin composition was determined by thioacidolysis. The sum of $\mathrm{H}, \mathrm{G}$, and $\mathrm{S}$ is expressed in $\mu$ mol per $\mathrm{g}$ acetyl bromide lignin. $\% \mathrm{H}+\% \mathrm{G}+$ $\% \mathrm{~S}=100$; other units are expressed versus $\mathrm{H}+\mathrm{G}+\mathrm{S}$. The data represent means \pm standard deviation (for biomass measurements: wild type, CCR2 ( $-/+$ ) and CCR2( $+/-$ ), $n=6$ biologically independent samples and $\operatorname{CCR} 2\left(-/^{*}\right)$ line $12, \operatorname{CCR} 2(-/+), \operatorname{CCR} 2(+/-), n=7$ biologically independent samples; for cell wall analysis: wild type and CCR2 $\left(-/^{*}\right)$ line $12, n=7$ biologically independent samples, CCR2 $(-/+)$ and $C C R 2(+/-), n=6$ biologically independent samples). ${ }^{\star \star} P<0.01$, one-way ANOVA with Dunnett's post hoc test; the exact $P$ value (for the pairwise comparison with the wild type) is shown between parentheses in the table. The status of the CCR2 alleles present in $P$. tremula $\times P$. alba is denoted between the parentheses; the first one represents that of the $P$. tremula allele, the second one represents that of the $P$. alba allele; + , wild type; - , knockout; ${ }^{*}$, protein-modified. Source data are provided as a Source data file.

Fig. 5). After debarking the harvested stems, the typical red coloration of the xylem was seen to be present in CCR2 $\left(-/^{*}\right)$ line 12 , but absent in the wild-type and the CCR2 monoallelic knockout plants (Fig. 6). These observations indicate that the lignin of the CCR2 monoallelic knockout plants resembles that of the wild type and not that of CCR $2\left(-/^{*}\right)$ line 12 . To validate this, the lignin content and composition of dried debarked stem material were determined (Table 2). The acetyl bromide lignin content in the CWR from CCR2 monoallelic knockout plants was equal to that of the wild type, whereas that of the CCR2 $\left(-/^{*}\right)$ line 12 was reduced by $\sim 15 \%$. In agreement with the normal xylem coloration, no significant differences in thioacidolysis-released aromatic units were observed between the CCR2 monoallelic knockout plants and the wild type. Similar to the results of 20week-old stems, 11-week-old CCR2 $\left(-/^{*}\right)$ line 12 stems had a decreased frequency of $\mathrm{H}$ monomers and an increased frequency 


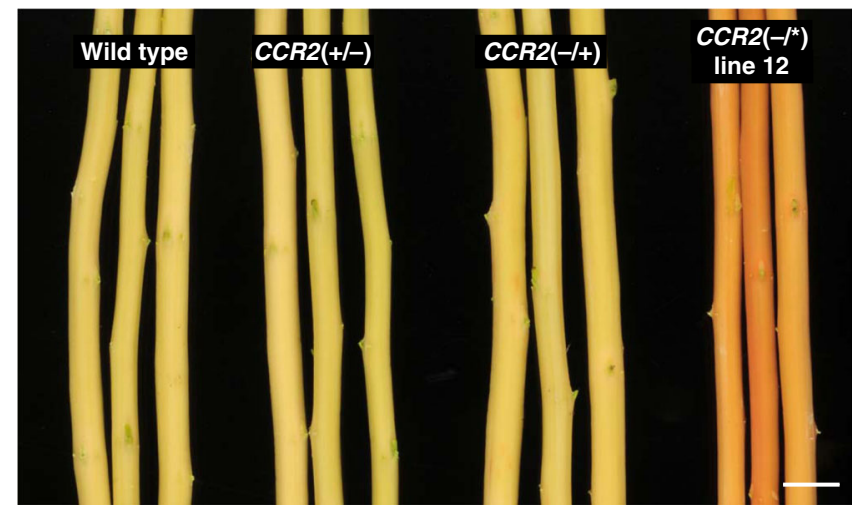

Fig. 6 Phenotype of debarked stems of CCR2( $+/-), \operatorname{CCR2}(-/+)$, and CCR2( $-/^{\star}$ ) line 12 poplars. Plants were grown for 11 weeks in the greenhouse. The red xylem phenotype was only present in $\operatorname{CCR} 2\left(-/^{\star}\right)$ line 12. The status of the CCR2 alleles present in $P$. tremula $\times P$. alba is denoted between the parentheses; the first one represents that of the $P$. tremula allele, the second one that of the P. alba allele; + , wild type; - , knockout; *, protein-modified. The stems shown are representative of seven biologically independent samples per line. Scale bar $=1 \mathrm{~cm}$.

of all three thioacidolysis-released ferulic acid units when compared to the wild-type and CCR2 monoallelic knockout plants.

Judged by the normal growth, lignin amount and lignin composition of the CCR2 monoallelic knockout plants, the $P$. tremula and the P. alba CCR2 alleles appear to both be haplosufficient in P. tremula $\times$ P. alba.

Phenolic profiling of the different CCR2 mutants. To further examine the haplo(in)sufficient status of the CCR2 alleles in $P$. tremula $\times P$. alba, and investigate to what extent the metabolic changes of CCR2 $\left(-/^{*}\right)$ line 12 reflect those expected from CCR2 deficiency, comparative phenolic profiling was performed via ultra-high-pressure liquid chromatography-mass spectrometry (UHPLC-MS) on debarked stems of wild type, CCR2 $(+/-)$, CCR2 $(-/+), \operatorname{CCR} 2\left(-/^{*}\right)$ line 12 , and CCR2(-/-). Principal component analysis (PCA) was performed on a total of 6182 peaks (mass-to-charge ratio $[\mathrm{m} / \mathrm{z}]$ features) (Supplementary Data 1). PCA showed that, according to the first principal component (which explains $53 \%$ of the variation), the metabolic profiles of wild type, CCR $2(+/-)$, and CCR2 $(-/+)$ were indistinguishable, whereas those of $C C R 2\left(-/^{*}\right)$ line 12 were situated between those of CCR2(-/-) and wild type (Fig. 7a). The second principal component, which explains $10.1 \%$ of the variation, reflects variation within the genotypes (and not between the genotypes) and can be attributed to biological and/or technical variation. Next, univariate statistical analysis was applied to the selected peaks to screen for peaks with significantly different intensities in CCR2 $(+/-), C C R 2(-/+), C C R 2(-/ *)$ line 12 , or CCR2(-/-) mutants compared with their levels in wild-type plants. After applying specific filters (see "Methods"), no significant differences were found between either CCR2 $(+/-)$ or CCR2 (-I+) and the wild type (Fig. $7 \mathrm{~b}$ ), again showing that the $P$. tremula and the $P$. alba CCR2 alleles are both haplosufficient in $P$. tremula $\times P$. alba. The reduction in lignin amount in CCR2 $\left(-/^{*}\right)$ line 12 is therefore not solely a consequence of the P. tremula CCR2 null allele.

By contrast, using the same specific filters, 960 and 1815 peaks were found to have a higher intensity in CCR $2\left(-1^{*}\right)$ line 12 and CCR2(-/-), respectively, when compared to the wild type, of which 800 were in common (Fig. 7c, d). In addition, 258 and 1854 peaks had a lower intensity in CCR2 $\left(-/^{*}\right)$ line 12 and
CCR2(-I-), respectively, when compared to the wild type, of which 199 were in common. Next, the top 10 highest peaks with significantly higher and lower intensities in CCR2(-/*) line 12 were structurally characterized based on their mass-to-charge ratio $(\mathrm{m} / \mathrm{z})$, retention time, and tandem mass spectrometry (MS/ MS) (Supplementary Figs. 6-11, Supplementary Table 4). The ten highest peaks with significantly higher intensities in CCR2 $\left(-/^{*}\right)$ line 12 could be assigned to ten compounds, of which seven could be (partially) structurally characterized as conjugates of ferulic acid, vanillic acid, sinapic acid, and caffeic acid, and three remained unknown. The ten highest peaks with significantly lower intensities in CCR2 $\left(-/^{*}\right)$ line 12 could be assigned to nine compounds, of which five could be structurally characterized as oligolignols, and four remained unknown.

The relatively high fraction of differential peaks that CCR2 $\left(-/^{*}\right)$ line 12 shares with CCR2(-/-) (Fig. 7d, Supplementary Table 4), and the identities of the differential compounds in $\operatorname{CCR} 2\left(-/^{*}\right)$ line 12 , which are in line with the position of CCR2 in the lignin biosynthetic pathway (Supplementary Table 4), again underline the haploinsufficiency of the mutant P. alba CCR2 allele in CCR2 $\left(-/^{*}\right)$ line 12.

A haploinsufficient $P$. alba CCR2 allele in CCR2(-/*) line 12. In CCR2 $\left(-/^{*}\right)$ line 12 , the $P$. alba CCR2 protein sequence differs in only two amino acids from the wild-type $P$. alba CCR2 protein sequence (Supplementary Fig. 2). Because the analysis of monoallelic CCR2 mutants suggested that the wild-type CCR2 alleles are haplosufficient in P. tremula $\times P$. alba (Table 2, Fig. 7), the reduced lignin content of $C C R 2\left(-/^{*}\right)$ line 12 is probably the consequence of the mutation in the P. alba CCR2 allele (in combination with the null $P$. tremula CCR2 allele), which might encode an enzyme with a lower CCR activity or a lower protein stability as compared to the wild-type $P$. alba CCR2-encoded enzyme. To validate this, yeast assays were performed in which the activities of the wild-type and the mutant $P$. alba CCR2 proteins were investigated based on the production of coniferaldehyde from feruloyl-CoA, the substrate of CCR2.

As it was not possible to feed feruloyl-CoA to the yeast cultures, whereas it was possible to feed ferulic acid, we created yeast strains that express 4-coumarate:CoA ligase (4CL). The 4CL enzyme converts ferulic acid to feruloyl-CoA, allowing the CCR2 enzyme activities to be tested (Fig. 8a). All yeast cultures were fed with ferulic acid and extracts were analyzed by GC-MS. Yeast cultures expressing only $4 C L$ produced no coniferaldehyde upon feeding with ferulic acid (Fig. 8b). However, upon co-expression of $4 C L$ and wild-type P. alba CCR2, coniferaldehyde was formed (peak 1, Fig. 8b; Supplementary Fig. 12a, b). In addition to coniferaldehyde, two other metabolites, which were identified based on their EI-MS spectra as dihydroconiferyl alcohol and coniferyl alcohol (peak 2 and peak 3, respectively), accumulated in this strain (Fig. 8b; Supplementary Fig. 12c, d). As these two metabolites also accumulated in yeast cultures expressing only $4 C L$ and additionally fed with coniferaldehyde (Fig. 8b), we concluded that yeast cells further metabolize coniferaldehyde to dihydroconiferyl alcohol and coniferyl alcohol. Therefore, these two metabolites can be used as additional diagnostic markers for the production of coniferaldehyde in yeast cultures.

In contrast to yeast cultures expressing both $4 C L$ and the wildtype CCR2, yeast cultures expressing $4 C L$ and the mutated P. alba CCR2 failed to produce coniferaldehyde, dihydroconiferyl alcohol, and coniferyl alcohol (Fig. 8b). Based on these data, we concluded that, in yeast, no detectable enzymatic activity was present for the mutant $P$. alba CCR2 protein. The normal growth but reduced lignin content of CCR2 $\left(-/^{*}\right)$ line 12 suggests that, in planta, the mutant $P$. alba CCR2 protein had a reduced CCR 
a

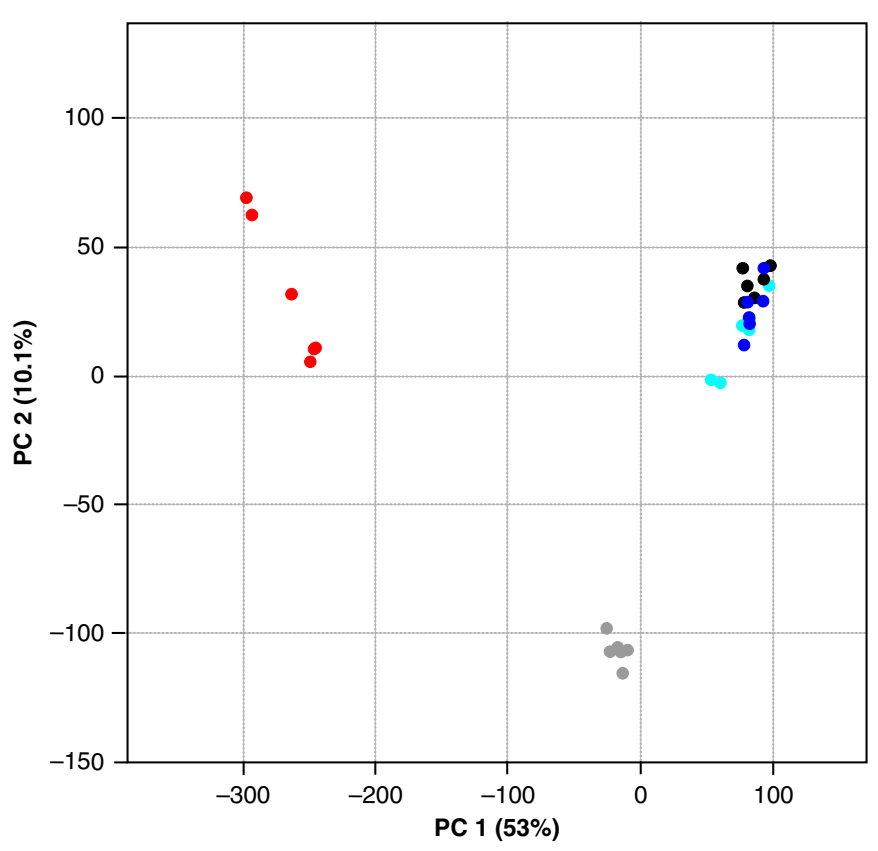

C
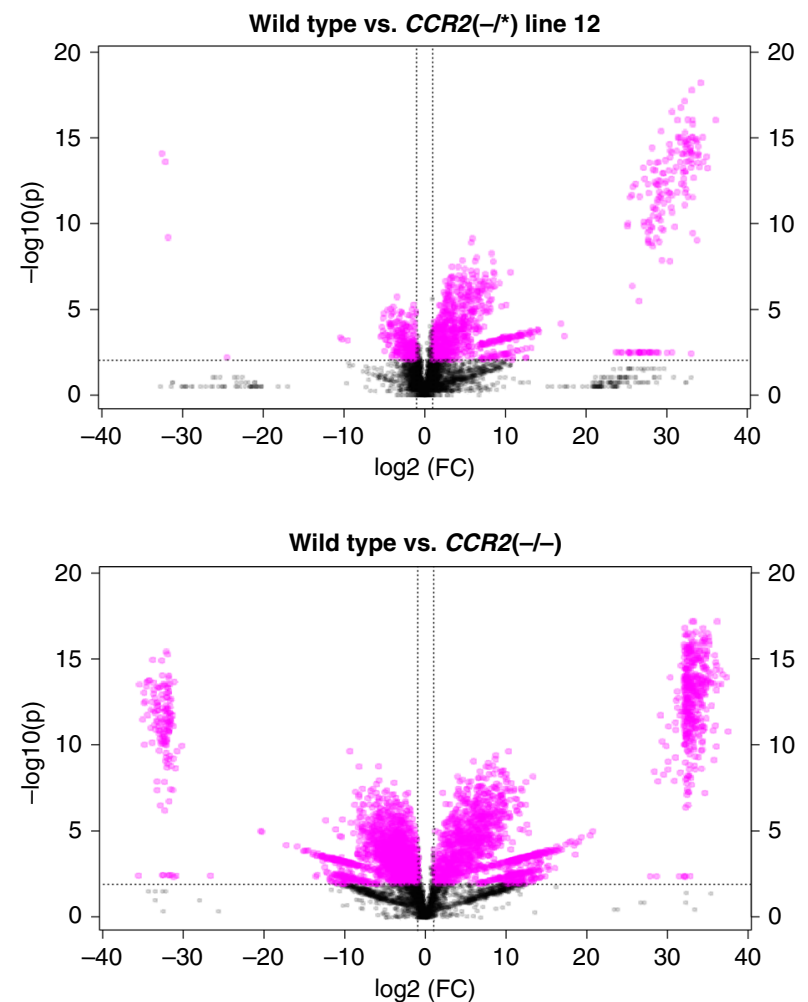

b
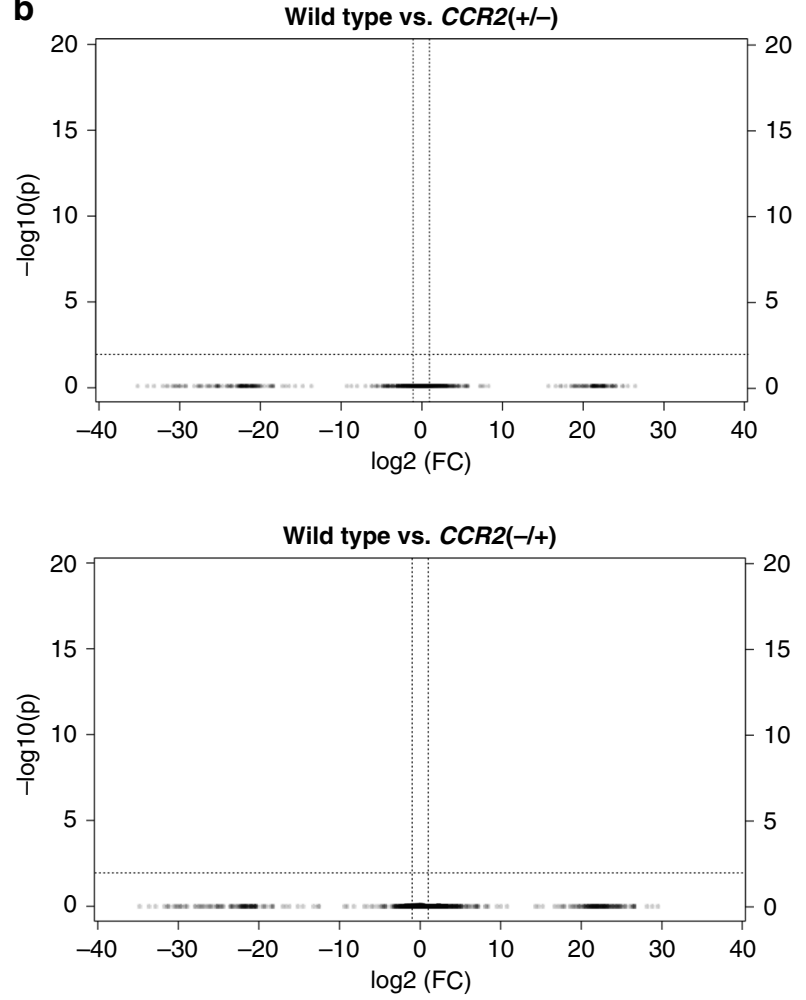

d
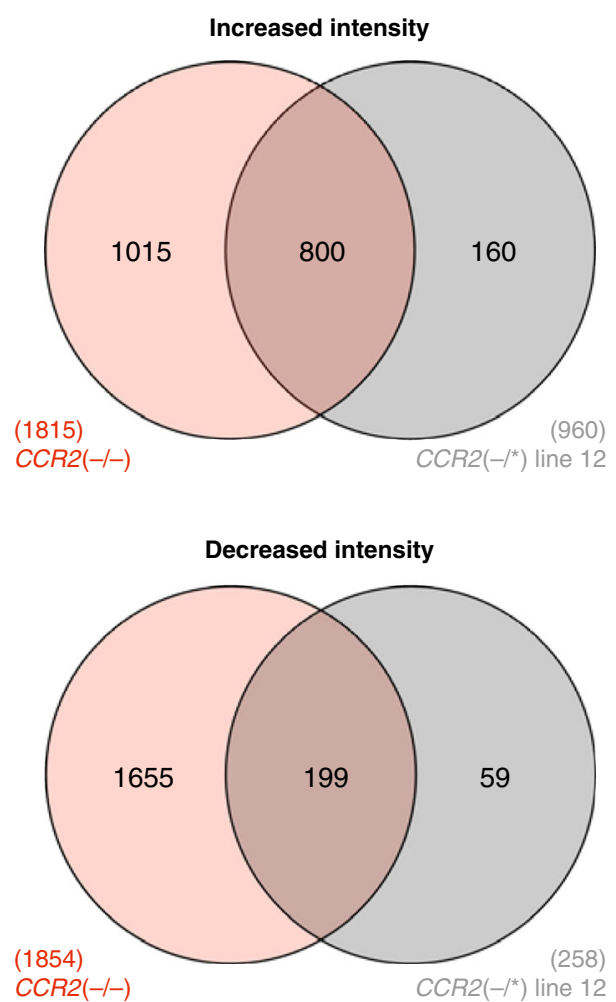

Fig. 7 Phenolic profiling of CCR2( $+/-), \mathbf{C C R 2}(-/+), \mathbf{C C R 2}\left(-/^{\star}\right)$ line 12, and $\left.\mathbf{C C R 2 (}-/-\right)$ stems. Plants were grown for 11 weeks in the greenhouse. a Plot of principal component 1 (PC1) and PC2 of principal component analysis (PCA) on 6182 peaks. Black dots, wild type; blue dots, CCR2(+/-); cyan dots, CCR2 $(-/+)$; gray dots, CCR2 $\left(-/^{*}\right)$ line 12 ; red dots, CCR2 $(-/-)$. b, c Volcano plots visualizing the differences between $\mathbf{b}$ wild type and CCR2 $(+/-)$ or CCR2 $(-/+)$, and $\mathbf{c}$ wild type and CCR2 $\left(-/^{*}\right)$ line 12 or CCR2 $(-/-)$. Magenta and black dots represent peaks that are different and not different in intensity, respectively, based on the filters: fold change $(F C)>2$ and $P$ value $<0.01$ (one-way ANOVA with Dunnett's post hoc test). $\mathbf{d}$ Venn diagrams of the number of peaks with significantly differential intensities (magenta dots from the volcano plots in (c)) between wild type and either CCR2( $\left./ /^{\star}\right)$ line 12 or CCR2 $(-/-)$. Wild type, $n=6$ biologically independent samples; CCR2 $\left(-/^{\star}\right)$ line $12, n=6$ biologically independent samples; CCR2 $(-/-), n=5$ biologically independent samples. 


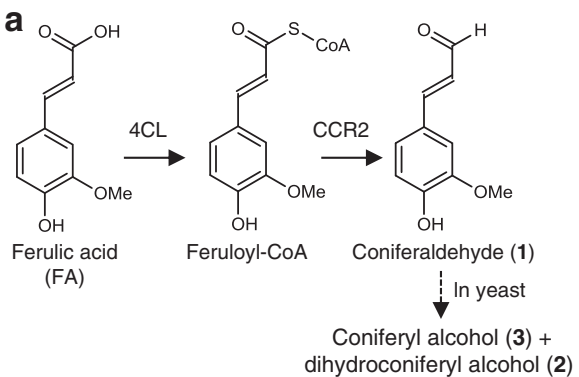

b
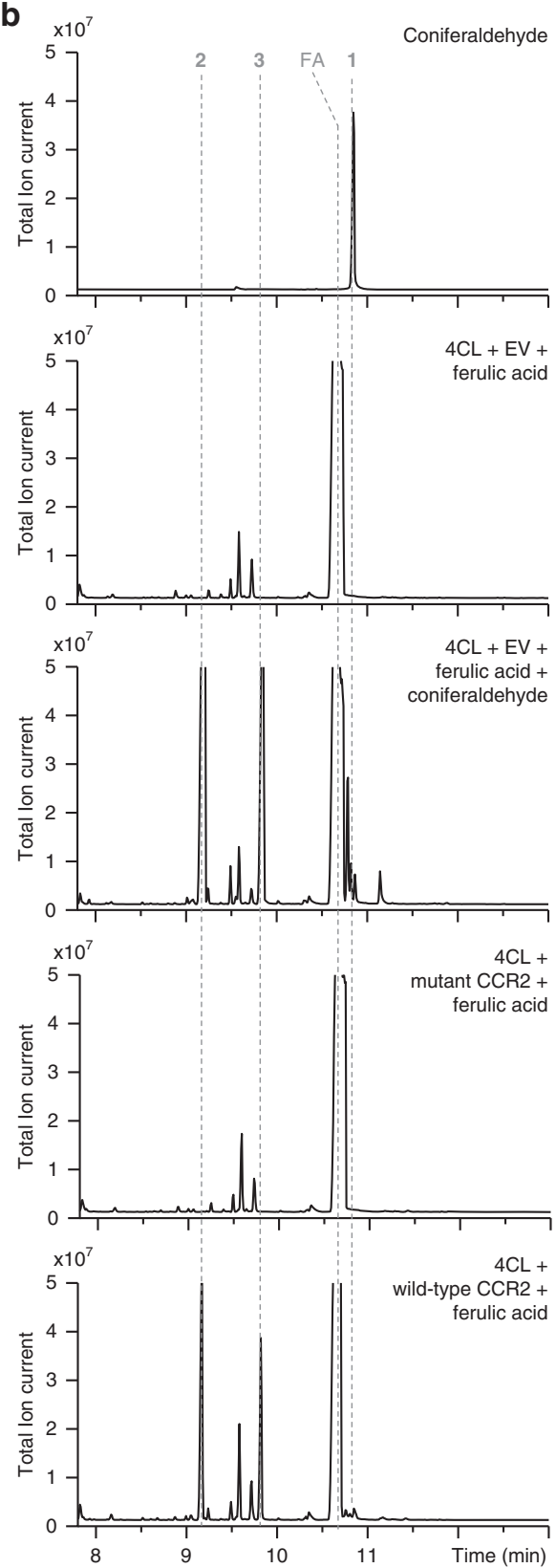

activity and/or reduced protein stability as compared to the wildtype $P$. alba CCR 2 protein, but did not fully lose its activity, as this would lead to dwarfism as observed in the CCR2 $(-/-)$ knockout mutants. The apparent null-activity in yeast might be explained by the lack of the proper cellular context of a normal lignifying cell, such as $\mathrm{pH}$, interaction, and/or stabilization partners, etc., which might influence CCR2 enzymatic activity.
Fig. 8 CCR2 activity assays in yeast. The relative activity of the mutant $P$. alba CCR2 protein (as present in CCR2 $\left(-/^{*}\right)$ line 12) was determined in yeast. a Principle of the yeast feeding assay. Yeast cultures were engineered to express $4 \mathrm{CL}$ and the wild-type $P$. alba CCR2 protein or mutated $P$. alba CCR2 protein (as present in $\operatorname{CCR2}\left(-/^{\star}\right)$ line 12 ). After feeding the yeast cultures with ferulic acid, the activity of the respective CCR2 protein was judged based on the production of coniferaldehyde (the product of CCR2, peak 1), coniferyl alcohol (peak 2), and dihydroconiferyl alcohol (peak 3). See Supplementary Fig. 12 for the spectra of peaks 1-3. b GC-MS chromatograms of an authentic coniferaldehyde standard and extracts from ferulic acid-fed yeast cells expressing $4 C L$ in combination with either an empty vector (EV), mutant $P$. alba CCR2 or wild-type $P$. alba CCR2. The results shown are representative of five biologically independent samples.

Not all CCR2 $\left(-/^{*}\right)$ lines display a normal growth phenotype. Using gRNA3 targeting the fourth exon of CCR2, another CCR2 $\left(-/^{*}\right)$ line was obtained having an indel pattern in the CCR2 alleles that was similar to that present in the CCR2 alleles of CCR2 $\left(-/^{*}\right.$ ) line 12 (albeit in a different position of the CCR2 gene). CCR2 $\left(-/^{*}\right)$ line 206 contained a frameshift mutation (5-bp deletion) in the P. tremula CCR2 allele, and a deletion of 3 bp in the P. alba CCR2 allele (Supplementary Fig. 5b). The latter resulted in a substitution of Trp175 and Asp176 for a Tyr175 in the corresponding $P$. alba CCR2 protein sequence (Supplementary Fig. 13). The amino-acid change occurred in $a 6$ of the CCR2 protein, but not in the active site, NAPD-binding domain, or substrate-binding pocket residues ${ }^{9-11}$.

CCR2 $\left(-/^{*}\right)$ line 206 had a lignin amount and growth that was increased when compared to that of CCR2(-I-), but still severely reduced when compared to that of the wild type (Supplementary Fig. 14a, b, d). However, similar to CCR2 $(-/-)$ stems, CCR2 $\left(-/^{*}\right)$ line 206 stems also displayed a red xylem coloration and collapsed vessels (Supplementary Fig. 14c, d).

\section{Discussion}

In previously generated CCR2-downregulated poplars, the red xylem phenotype appeared in patches, even among clones originating from the same plant, as a consequence of unstable downregulation ${ }^{3}$. A similar observation was made for poplars with RNAi-mediated downregulation of $4 C L 1^{4}$. In contrast, CCR2(-/*) line 12 poplars had a stable reduction in lignin amount along the stem and in all biological replicates, as judged from the uniformly distributed red xylem phenotype, which is a big step forward in achieving stably modified lignocellulosic biomass.

After alkaline pretreatment, the cellulose-to-glucose conversion increased from $70.9 \%$ in wild type to an almost complete conversion (95.9\%) in CCR2 $\left(-/^{*}\right)$ line 12 . Also without pretreatment, CCR2 $\left(-/^{*}\right)$ line 12 had a $36 \%$ higher cellulose-to-glucose conversion than the wild type. Since no biomass penalty was observed for CCR $2\left(-/^{*}\right)$ line 12 , even on a plant basis, this line yielded substantially more sugar than the wild type upon limitedsaccharification experiments. However, before further translation of this knowledge to generate feedstock for the biorefinery, CCR2 $\left(-/^{*}\right)$ line 12 poplars remain to be evaluated for growth and lignin amount when cultivated in the field, where they are exposed to different biotic and abiotic stresses. Indeed, it has been shown that genetically modified trees that grow normally in the greenhouse do not always grow as well as wild type when grown in the field ${ }^{20}$. But even if CCR $2\left(-/^{*}\right)$ line 12 plants would have a yield penalty in the field, the specific mutation present in the $P$. alba CCR2 allele of CCR2 $\left(-/^{*}\right)$ line 12 might still be valuable to engineer lignin in another cultivar or crop (such as Eucalyptus), 
because the effect of a mutation on the phenotype depends not only on the environment, but also on the specific genetic background in which it resides ${ }^{21}$.

Typically, using CRISPR/Cas9, knockout lines are generated. However, knockout mutants in lignin biosynthesis frequently suffer from undesired phenotypes such as dwarfism ${ }^{6-8,18}$. Lignin levels in plants can be reduced without affecting plant growth, but if lignin drops below a critical level, effects on vessel architecture and growth become apparent ${ }^{7,8,18,22}$. For example, for CCR2downregulated (RNAi-mediated) poplars, a range of plants with different levels of CCR2 downregulation and growth was obtained (even amongst biological replicates originating from the same plant $)^{3}$. Approximately $5 \%$ of all CCR2-downregulated lines that have been generated displayed severe dwarfism and could only survive in tissue culture ${ }^{5}$. These lines were most likely the plants with the highest reduction in CCR2 activity. Of the CCR2downregulated plants that survived on soil, the plants with the highest amount of red coloration (and thus the lowest amount of CCR expression and lignin amount) had the highest increase in saccharification efficiency, but also showed collapsed vessels and suffered from a biomass yield penalty 3,5 . Stems with lower amounts of red coloration did not suffer from a yield penalty, but only had a marginal reduction in lignin and increase in saccharification efficiency. Here, a similar observation was made, but in individual, stably CRISPR/Cas9-edited poplars; CCR2(-/-) knock-outs had the lowest amounts of lignin and displayed collapsed vessels and severe dwarfism. CCR2 $\left(-/^{*}\right)$ line 206 had a slightly increased amount of lignin and biomass yield when compared to CCR2(-I-) but still displayed collapsed vessels, whereas CCR2 $\left(-/^{*}\right)$ line 12 , with its mild reduction in lignin amount compared to the wild type, displayed normal vessels and growth, even in clonally replicated trees. As the wild-type CCR2 alleles are both haplosufficient in $P$. tremula $\times P$. alba, the differences in lignin amount and growth between CCR2 $\left(-/^{*}\right)$ line 206 and line 12 could be attributed to the 3 bp deletions occurring in the fourth and third exon of P. alba CCR2 of CCR2(-/*) line 206 and line 12, respectively (see Supplementary Note 1 for an explanation of the impossibility of the off-target effect).

Our research shows that generating a range of allelic variants in the gene of interest by CRISPR/Cas9 is a useful strategy to pick up rare alleles that allow obtaining the desired (intermediate) phenotype (e.g., plants with reduced amounts of lignin without displaying a yield penalty, such as CCR2 $\left(-l^{*}\right)$ line 12). For haplosufficient genes in outbreeding diploid species (such as most tree species), an interesting strategy is to knock out one allele, while the other can be screened for mutations leading to (small) amino-acid modifications, as described in this paper. Alternatively, screening for lines in which both alleles contain mutations leading to (small) amino-acid modifications might also be valuable. The yeast assay shows that, although it seems to be a fast, cheap, and easy way to evaluate the activity of specific allelic variants-or even to screen for specific allelic variants with modified activity-the results obtained are not necessarily good predictors for the activity of such variants in planta. Therefore, a direct in planta screening for such variants is a better strategy.

\footnotetext{
Methods

Plant material and vector construction. To introduce biallelic mutations in CCR2, a list of 30 protospacers with the N20-NGG motif specific for the P. tremula $\times$ P. alba CCR2 alleles (Potri.003G181400) was extracted from the Aspen database (http://aspendb.uga.edu/) ${ }^{23,24}$. Next, the possible protospacers were analyzed based on their position in the CCR 2 alleles and the possible off-targets via the Aspen database $\mathrm{e}^{23,24}$. In addition, GC-content and absence of a TTTTT sequence were considered. Based on these parameters, the most suitable gRNA sequence was chosen: GACCAAAAATGTGATCATTG (gRNA1). gRNA1 targets the third exon of both CCR2 alleles. Using the pUC gRNA Shuttle (Addgene plasmid \#47024)
} plasmid, gRNA1 was cloned into the $201 N$ : $\operatorname{Cas} 9$ plasmid (Addgene plasmid
\#59175) by Gibson assembly ${ }^{25}$. The p201NCas9:gRNA1_CCR2 vector was transferred into Agrobacterium tumefaciens strain C58C1 pMP90 by electroporation. Agrobacterium-mediated transformation of $P$. tremula $\times$ P. alba 717-1B4 was performed via co-cultivation ${ }^{26}$. For this, 40 explants (which were preincubated on solidified M1 medium (see below) for $48 \mathrm{~h}$ at $24^{\circ} \mathrm{C}$ in the dark) were dipped into $25 \mathrm{~mL}$ of Agrobacterium solution (grown on $\mathrm{M}$ liquid medium (see below) until reaching a concentration of $5 \times 10^{8} \mathrm{cfu}$ per $\mathrm{mL}$ ) and slowly stirred for $16 \mathrm{~h}$. After blotting on sterile paper, the explants were placed on solidified M1 medium for $48 \mathrm{~h}$. Subsequently, the explants were washed with tetracycline solution ( $25 \mathrm{mg}$ per liter) and sterile water, and transferred onto M2 medium (see below) for 10 days at $24^{\circ} \mathrm{C}$. Transferring the explants to solid M3 medium (see below) with $100 \mathrm{mg}$ per liter kanamycin in standard light conditions yielded regenerated shoots that could be excised and transferred to M1/2 medium (see below) with $50 \mathrm{mg}$ per liter kanamycin. After growing for approximately 20 days in standard light conditions, the plants (that developed roots and elongated shoots) were micropropagated on $\mathrm{M} 1 / 2$ medium (see below) with $50 \mathrm{mg}$ per liter kanamycin.

To introduce monoallelic mutations in CCR2, specific gRNAs (targeting either the $P$. tremula or the $P$. alba CCR2 allele) were selected based on the criteria described above. The best suitable gRNA sequences were GTGGTATTG CTATGGAAAGG (gRNA2) and GGAACAAGCTGCATGGGATA (gRNA3). gRNA2 and gRNA3 target the fourth exon of the P. alba and P. tremula CCR2 allele, respectively. Cloning of the gRNAs in the $p 201 N$-Cas 9 vector, subsequent transformation into A. tumefaciens and poplar transformation were performed as described above.

For genotyping the regenerated, transformed shoots, the following primers pairs (designed using the Primer3 0.4.0 software) were used for PCR for identifying the mutations present in the CCR2 alleles. For the PCR using the DNA extracted from plants transformed with the construct containing gRNA1: forward $5^{\prime}$-TACAYGG TAATTAATGGTGG-3' ${ }^{\prime}$, reverse $5^{\prime}$-GATACCTTGGTGTTCTTGC-3' ${ }^{\prime}$; for gRNA2: forward 5'-AGCTTGCCCGTTCTGTGTT-3', reverse 5'-CGGTGAGGTACTTG AGGATG-3'; for gRNA3: forward 5'-ACCCCGTTCTGGTAGCTG-3', reverse $5^{\prime}$-GGAAGGCGTCTCAAAGACT-3'. The PCR products were sequenced by Eurofins (Eurofins Genomics) and analyzed via CLC Main Workbench 8.

The wild-type controls $(P$. tremula $\times P$. alba 717-1B4) originate from the same batch of plants that was used to generate the transgenic lines. However, instead of generating callus-tissue and performing Agrobacterium-mediated transformation, the wild-type controls were maintained and clonally propagated to serve as a control for the regenerated, transformed shoots.

For clonal propagation, poplars that were grown for 3 to 4 months in tissue culture (on M1/2 medium as described below) under long-day conditions (16-h light and 8-h dark photoperiod, $24^{\circ} \mathrm{C}$ ) were used. More specifically, the stems were cut into pieces of $\pm 2 \mathrm{~cm}$ and put on fresh M1/2 medium to allow the development of roots and new shoots.

Media used for plant cultivation. M: Murashige and Skoog basic medium (Duchefa) $4.4 \mathrm{~g}$ per liter, Morel and Wetmore vitamins $10 \mathrm{~mL}$ per liter, $L$-cystein $1 \mathrm{mg}$ per liter, $L$-glutamine $200 \mathrm{mg}$ per liter, sucrose $30 \mathrm{~g}$ per liter, plant agar (Duchefa) $6.2 \mathrm{~g}$ per liter.

M1/2: as $M$ but with half-strength macro-nutrients, sucrose $20 \mathrm{~g}$ per liter,

IAA $3 \mu \mathrm{M}$.

M1: as $\mathrm{M}$ but with NAA $10 \mu \mathrm{M}$ and 2 iP $5 \mu \mathrm{M}$.

M2: as M1 but with carbenicillin $500 \mathrm{mg}$ per liter, cefotaxime $250 \mathrm{mg}$ per liter. M3: as $\mathrm{M}$ but with carbenicillin $500 \mathrm{mg}$ per liter, cefotaxime $250 \mathrm{mg}$ per liter, thidiazuron $0.1 \mu \mathrm{M}$.

Plant growth and harvest. After growing for four months in tissue culture under long-day conditions, the transgenic poplars and their wild-type controls were transferred to soil. More specifically, the poplars were transferred to pots of $5.5-\mathrm{cm}$ diameter filled with Saniflor commercial soil (Van Israel nv), placed in a tray filled with water, and covered with a cage liner (Tecniplast APET disposable cage liner for cage body $1291 \mathrm{H}$ ) for acclimatization. After 2 weeks, one side of the cage liner was lifted $1 \mathrm{~cm}$ above water level and kept accordingly for 1 day, after which the other side also was lifted. The next day, the cage liner was removed and the acclimatized plants were transferred to bigger pots filled with a Saniflor commercial soil (Van Israel nv) (10 liter). Note that CCR2 (-/-) plants were found to be extremely sensitive to the adjustment to greenhouse conditions. Therefore, here, the cage liner was kept closed for a period of 5 weeks and slowly opened over a period of 3 weeks to allow a much slower transition to the less-humid greenhouse conditions. Even with this precautionary measure, only a small number of CCR2 (-/-) poplars recovered, whereas all plants of the other genotypes survived. In total, six batches of plants were grown for 11 or 20 weeks in the greenhouse under a 16-h light and 8-h dark photoperiod at $\sim 21^{\circ} \mathrm{C}$.

The first batch, containing wild type, the 20 individual CCR2(-/-) lines, and $\operatorname{CCR} 2\left(-/^{*}\right)$ line 12 , was grown for 11 weeks in the greenhouse and used for a picture of the growth phenotype (Fig. 1).

The second batch, containing wild type and CCR $2\left(-/^{*}\right)$ line 12 , was grown for 20 weeks in the greenhouse. The height of the trees was determined weekly (Fig. 2a, b). After that, the diameter of the stems was determined $(3 \mathrm{~cm}$ above soil level) (Table 1). Next, the stems were harvested ( $40 \mathrm{~cm}$ above soil level), the leaves were removed from the stem and the fresh weight of the stems was determined before 
and after removing the bark (Table 1). The dry weight of the debarked stems was determined after air-drying the stems for 2 weeks at ambient temperature (Table 1). The dried, debarked stem was ground in a ball mill for cell wall analysis and saccharification assays (Table 1, Fig. 4, Supplementary Tables 2 and 3).

The third batch consisted of the same lines present in batch 2 (wild type and CCR $2\left(-/^{*}\right)$ line 12$)$, but now also accompanied by CCR $2(-/-)$ mutants. These plants were also grown for 20 weeks in the greenhouse. For wild type and CCR2 $\left(-/^{*}\right)$ line $12,5-\mathrm{cm}$-long stem parts between 15 and $20 \mathrm{~cm}$ (relative to the soil) were harvested, debarked, and stored in tap water for 1 day. For CCR2 $(-1-)$, the 3$\mathrm{cm}$-long stem parts between 3 and $6 \mathrm{~cm}$ (relative to the soil) were harvested, debarked, and stored in tap water for 1 day. These stem pieces were used for microscopy (Fig. 3).

The fourth batch, containing wild type, CCR2 $(+/-)$, CCR2 $(-/+)$, and CCR2 $\left(-/^{*}\right)$ line 12 , was grown for 11 weeks in the greenhouse. After that, the diameter of the stems was determined $(3 \mathrm{~cm}$ above soil level). Next, the stems were harvested $(5 \mathrm{~cm}$ above soil level), and the fresh weight was determined after removing the leaves and bark. The dry weight was determined after drying the stems for 5 days at $50{ }^{\circ} \mathrm{C}$ (Table 2). For acetyl bromide and thioacidolysis (Table 2), the harvested stems were debarked, air-dried, and ground in a ball mill (Fig. 6).

The fifth batch consisted of the same lines present in batch 4 (wild type, CCR2 $(+/-), C C R 2(-/+)$, and $\operatorname{CCR} 2\left(-/^{*}\right)$ line 12$)$, but now also accompanied by CCR 2 $(-/-)$ mutants (Fig. 5). After growing for 11 weeks in the greenhouse, the stems were harvested $(5 \mathrm{~cm}$ above soil level) and the bottom $10 \mathrm{~cm}$ of the harvested stem piece was debarked, snap-frozen in liquid nitrogen, and stored at $-70^{\circ} \mathrm{C}$ for metabolomics (Fig. 7, Supplementary Table 4, Supplementary Figs. 6-11).

The sixth batch, containing wild type, CCR2 $\left(-/^{*}\right)$ line 206 , and CCR2 $(-/-)$ was grown for 20 weeks in the greenhouse. The height of the trees was determined weekly (Supplementary Fig. 14a-c). For the wild type, CCR2 $\left(-/^{*}\right)$ line 206, and CCR2 $(-/-)$, the stems were harvested 10,3 , and $3 \mathrm{~cm}$ above soil level, respectively. Of each harvested wild-type, CCR $2\left(-I^{*}\right)$ line 206 , and CCR $2(-/-)$ stem pieces, the basal 3,1 , and $1 \mathrm{~cm}$, respectively, was debarked and stored for 3 days in tap water for microscopy (Supplementary Fig. 14d).

Microscopy. Fifteen-micrometer-thick stem slices were made using a ReichertJung 2040 Autocut Microtome (Leica). Sections were stained with Wiesner and Mäule reagents; Wiesner staining was performed by adding a drop of phloroglucinol-HCl solution (consisting of one volume of concentrated $\mathrm{HCl}(37 \mathrm{M})$ and two volumes of $3 \%$ phloroglucinol in ethanol) to the sections. Mäule staining was performed by incubating the sections in $0.5 \%(\mathrm{w} / \mathrm{v})$ potassium permanganate for $5 \mathrm{~min}$, followed by washing with distilled water. Next, the sections were incubated in concentrated $\mathrm{HCl}(37 \mathrm{M})$, followed by the addition of concentrated ammonium hydroxide solution.

Images were acquired using an Olympus BX51 microscope (Olympus) with an Olympus PlanC N 10x (0.25 NA) objective or Olympus UplanFl N 20x (0.50 NA) objective and the Toupview x64,3.7.10121 software. Sections were also imaged via autofluorescence using a Zeiss Axio Imager.M1 microscope (Carl Zeiss) with a Plan-Apochromat 10X (0.45 NA) objective and the AxioVs40 V4.8.2.0 software. A $365-\mathrm{nm}$ excitation filter was used together with a $395-\mathrm{nm}$ beamsplitter and a $420-$ to $470-\mathrm{nm}$ bandpass emission filter.

Cell wall characterization. To determine the matrix polysaccharides, cellulose, and lignin characteristics, ground wood powder was used for preparing cell wall residue by sequentially washing for $30 \mathrm{~min}$ each with milliQ water at $98^{\circ} \mathrm{C}$, ethanol at $76^{\circ} \mathrm{C}$, chloroform at $59^{\circ} \mathrm{C}$, and acetone at $54^{\circ} \mathrm{C}$. The remaining CWR was dried under vacuum.

To determine the crystalline cellulose amount, the Updegraff method ${ }^{27}$ was used on $10 \mathrm{mg}$ of CWR. First, the samples were incubated with $1 \mathrm{~mL}$ trifluoroacetic acid $(2 \mathrm{M})$ for $2 \mathrm{~h}$ at $99^{\circ} \mathrm{C}$ while shaking at $750 \mathrm{rpm}$, followed by centrifugation for $3 \mathrm{~min}$ at $19,757 \times g$. Next, the pellet was washed three times with $1 \mathrm{~mL}$ milliQ water, two times with $1 \mathrm{~mL}$ acetone, dried under vacuum, and weighed. The weight loss upon trifluoroacetic acid digestion was used to determine the matrix polysaccharide content (including hemicelluloses, pectins, and amorphous cellulose). Subsequently, $1 \mathrm{~mL}$ of Updegraff reagent (consisting of eight volumes of acetic acid, one volume of nitric acid, and 2 volumes of milliQ water) was added to the pellet, followed by vortexing and heating at $99^{\circ} \mathrm{C}$ for $30 \mathrm{~min}$. After centrifuging the samples for $15 \mathrm{~min}$ at $10,080 \times g$, the supernatant was discarded without disturbing the pellet. Next, the pellet was washed one time with $1 \mathrm{~mL}$ water and two times with $1 \mathrm{~mL}$ acetone. After drying under vacuum, the pellet was incubated with $175 \mu \mathrm{L}$ of $72 \%(\mathrm{v} / \mathrm{v})$ sulfuric acid for $30 \mathrm{~min}$ at room temperature. Next, the samples were vortexed and incubated for another $15 \mathrm{~min}$ at room temperature.

After adding $825 \mu \mathrm{L}$ of water, the samples were centrifuged for $5 \mathrm{~min}$ at $10,080 \times g$. To wells of a 96-well plate, $5 \mu \mathrm{L}$ of supernatant, $95 \mu \mathrm{L}$ of water and $200 \mu \mathrm{L}$ of freshly prepared anthrone reagent $(2 \mathrm{mg}$ anthrone per $\mathrm{mL}$ pure sulfuric acid) was added. The plate was sealed and incubated for $30 \mathrm{~min}$ at $80^{\circ} \mathrm{C}$. After cooling down to room temperature, the absorption was measured at $625 \mathrm{~nm}$ with a NanoDrop ${ }^{\circledast}$ ND-1000 spectrophotometer (Thermo Scientific). The Nanodrop 1000 3.8.1 software was used for collecting the absorption data.

Lignin content was determined by the acetyl bromide protocol ${ }^{18,28}$ on $5 \mathrm{mg}$ of CWR, and the Klason protocol ${ }^{7,29}$ on $100 \mathrm{mg}$ of CWR. In the acetyl bromide protocol, the samples were incubated in $250 \mu \mathrm{L}$ freshly made acetyl bromide solution (25\% acetyl bromide in glacial acetic acid) for $2 \mathrm{~h}$ at $50^{\circ} \mathrm{C}$. Next, the samples were incubated for another hour at $50^{\circ} \mathrm{C}$ with vortexing every $15 \mathrm{~min}$. After cooling the samples on ice and centrifuging for $15 \mathrm{~min}$ at $10,080 \times g, 100 \mu \mathrm{L}$ supernatant, $75 \mu \mathrm{L}$ freshly made hydroxylamine hydrochloride $(0.5 \mathrm{M}), 400 \mu \mathrm{L}$ $\mathrm{NaOH}(2 \mathrm{M})$, and $1.425 \mathrm{~mL}$ glacial acetic acid were added to an empty $2-\mathrm{mL}$ Eppendorf. The lignin concentrations were determined by measuring the absorbance at $280 \mathrm{~nm}$ with a NanoDrop ${ }^{\circledast} \mathrm{ND}-1000$ spectrophotometer (Thermo Scientific) and applying the Bouguer-Lambert-Beer law. The Nanodrop 1000 3.8.1 software was used for collecting the absorption data. In the Klason protocol, the samples were incubated with $1 \mathrm{~mL}$ sulfuric acid $(72 \%)$ in 15 -mL glass vials for $2 \mathrm{~h}$ at room temperature while stirring. After transferring the samples to a $100-\mathrm{mL}$ flask, $13.4 \mathrm{~mL}$ of milliQ water was added. The flasks were autoclaved for $1 \mathrm{~h}(1 \mathrm{bar}$ $121{ }^{\circ} \mathrm{C}$ ). Next, the samples were incubated for $16 \mathrm{~h}$ at $4{ }^{\circ} \mathrm{C}$. To measure the acidsoluble lignin, $1 \mathrm{~mL}$ of supernatant was collected (see further). The remaining samples were filtered and washed extensively with $200 \mathrm{~mL}$ of milliQ water through a preweighed filter paper (Sartorius AG) using a Büchner filter system (Merck Millipore). The filter papers were dried for $16 \mathrm{~h}$ at $105^{\circ} \mathrm{C}$ and cooled down for $1 \mathrm{~h}$ at room temperature. The lignin amount was determined gravimetrically. For determining the acid-soluble lignin, the previously collected $1 \mathrm{~mL}$ of supernatant was centrifuged and diluted 20 times in milliQ water. The absorbance at $205 \mathrm{~nm}$ was measured using a spectrophotometer (Genesys $10 \mathrm{~S}$ UV-Vis, Thermo

Scientific). The acid-soluble lignin concentrations were calculated by means of the Bouguer-Lambert-Beer law.

For the lignin composition determination via thioacidolysis ${ }^{14,30}, 15 \mathrm{mg}$ of CWR was weighed into a 5-mL glass Wheaton vial with Teflon-lined screw-cap. First, the samples were incubated with $1 \mathrm{~mL}$ reaction mixture (consisting of $2.5 \%$ boron trifluoride etherate and $10 \%$ ethanethiol in dioxane) for $4 \mathrm{~h}$ at $98^{\circ} \mathrm{C}$, while shaking the vials manually every half an hour. Next, the samples were incubated for $5 \mathrm{~min}$ at $-20{ }^{\circ} \mathrm{C}$. To the samples, $0.2 \mathrm{~mL}$ tetracosane in dichloromethane $(5 \mathrm{mg}$ per $\mathrm{mL})$ and $0.3 \mathrm{~mL}$ of $0.4 \mathrm{M}$ sodium bicarbonate was added. Next, the samples were extracted by adding $2 \mathrm{~mL}$ milliQ water and $1 \mathrm{~mL}$ dichloromethane. By using a Pasteur pipette packed with a small cotton plug and a spatula-point of anhydrous sodium sulfate, $0.5 \mathrm{~mL}$ of the organic phase was filtered and added to a new Eppendorf. The samples were dried under vacuum and resuspended in $0.2 \mathrm{~mL}$ dichloromethane. Derivatisation occurred by adding $20 \mu \mathrm{L}$ pyridine and $100 \mu \mathrm{L} N$, $O$-bis(trimethylsilyl) acetamide to $20 \mu \mathrm{L}$ of resuspended sample and incubating the samples for $2 \mathrm{~h}$ at $25^{\circ} \mathrm{C}$ while shaking at $750 \mathrm{rpm}$. The reaction product was analyzed by GC-MS. GC-MS analysis was carried out using a 7890B GC system equipped with a 7693A Automatic Liquid Sampler and a 7250 Accurate-Mass Quadrupole Time-of-Flight MS system (Agilent Technologies). One microliter of the reaction product was injected in splitless mode with the injector port set to $280^{\circ} \mathrm{C}$. Separation was realized with a VF- $5 \mathrm{~ms}$ column $(30 \mathrm{~m} \times 0.25 \mathrm{~mm}, 0.25 \mu \mathrm{m}$; Varian CP9013; Agilent Technologies) with helium carrier gas at a constant flow of $1.2 \mathrm{~mL}$ per min. The oven was held at $130^{\circ} \mathrm{C}$ for $3 \mathrm{~min}$ post-injection, ramped to $200^{\circ} \mathrm{C}$ at $10^{\circ} \mathrm{C}$ per min, ramped to $250^{\circ} \mathrm{C}$ at $3^{\circ} \mathrm{C}$ per min, held at $250^{\circ} \mathrm{C}$ for $5 \mathrm{~min}$, ramped to $320^{\circ} \mathrm{C}$ at $20^{\circ} \mathrm{C}$ per min, held at $320^{\circ} \mathrm{C}$ for $5 \mathrm{~min}$, and finally cooled to $130^{\circ} \mathrm{C}$ at $50^{\circ} \mathrm{C}$ per min at the end of the run. The MSD transfer line was set to $280^{\circ} \mathrm{C}$ and the electron ionization energy was $70 \mathrm{eV}$. Full EI-MS spectra were recorded between $\mathrm{m} / \mathrm{z} 50$ and 800 at a resolution of $>25,000$ and with a solvent delay of $10.0 \mathrm{~min}$. Peak integrations for quantification of the lignin monomers were carried out using the MassHunter Quantitative Analysis (for QTOF) software package (Agilent Technologies).

For the lignin composition determination via $\mathrm{NMR}^{31-33}, 40-50 \mathrm{mg}$ of ground stem powder was suspended in $0.6 \mathrm{~mL}$ DMSO- $\mathrm{d}_{6}:$ pyridine- $_{5}(4: 1, \mathrm{v} / \mathrm{v})$. The samples were sonicated, with occasional mixing by vortexing, until a uniform gel was formed. NMR experiments were performed on a Bruker Biospin (Billerica) Avance $700 \mathrm{MHz}$ spectrometer equipped with a $5-\mathrm{mm}$ QCI ${ }^{1} \mathrm{H} /{ }^{31} \mathrm{P} /{ }^{13} \mathrm{C} /{ }^{15} \mathrm{~N}$ cryoprobe with inverse geometry (proton coils closest to the sample). As in internal reference, the central DMSO solvent peak was used $\left(\delta_{\mathrm{C}} 39.5, \delta_{\mathrm{H}} 2.49 \mathrm{ppm}\right)$. The ${ }^{1} \mathrm{H}-{ }^{13} \mathrm{C}$ correlation experiment was an adiabatic HSQC experiment (Bruker standard pulse sequence 'hsqcetgpsisp2.2'; phase-sensitive gradient-edited-2D HSQC using adiabatic pulses for inversion and refocusing). The parameters used for the HSQC experiments were acquired from 10 to $0 \mathrm{ppm}$ in F2 $\left({ }^{1} \mathrm{H}\right)$ with 1398 data points (acquisition time, $100 \mathrm{~ms}$ ) and 200 to $0 \mathrm{ppm}$ in $\mathrm{F} 1\left({ }^{13} \mathrm{C}\right)$ with 570 increments ( $\mathrm{F} 1$ acquisition time, $8 \mathrm{~ms}$ ) of 32 scans with a $1 \mathrm{~s}$ interscan delay. The $\mathrm{d}_{24}$ delay was set to $0.86 \mathrm{~ms}(1 / 8 \mathrm{~J}, \mathrm{~J}=145 \mathrm{~Hz})$. The total acquisition time for a sample was $\sim 5 \mathrm{~h}$. Processing used typical matched Gaussian apodization $(\mathrm{GB}=$ $0.001, \mathrm{LB}=-0.5)$ in $\mathrm{F} 2$ and Gaussian apodization $(\mathrm{GB}=0.001, \mathrm{LB}=-0.3)$ also in F1 (without using linear prediction). Volume integration of contours in HSQC plots used TopSpin 4.0.8 software, and no correction factors were used.

Analytical gel-permeation chromatography. Ground powder $(\sim 150 \mathrm{mg})$ was treated with cellulase (5 $\mathrm{wt} \%$ to biomass) in sodium acetate buffer (pH $5.0,40 \mathrm{~mL}$ ) at $37^{\circ} \mathrm{C}$ for $72 \mathrm{~h}$. After centrifugation, the precipitate was collected and washed five times with deionized water to obtain enzyme lignin for gel-permeation chromatography (GPC) analysis.

Enzyme lignin $(\sim 10 \mathrm{mg})$ was dissolved in dimethylformamide (DMF)/lithium bromide (LiBr) $(700 \mu \mathrm{L}, 0.1 \mathrm{M} \mathrm{LiBr})$ solution and filtered through a syringe filter $(0.45 \mu \mathrm{m}, \mathrm{PVDF})$. GPC analysis was performed utilizing a Shimadzu LC20-AD LC pump equipped with a Shimadzu SPD-M20A UV-vis detector set at $280 \mathrm{~nm}$ and a 
Shimadzu RID-10A refractive index detector. The GPC column set consists of 4 TOSOH (TOSOH Bioscience, LLC) GPC columns and a guard column (TSKgel Guard Alpha $6.0 \mathrm{~mm} \mathrm{ID} \times 4.0 \mathrm{~cm}, 13 \mu \mathrm{m} \rightarrow$ TSKgel Alpha-M $7.8 \mathrm{~mm} \mathrm{ID} \times 30 \mathrm{~cm}$, $13 \mu \mathrm{m} \rightarrow$ TSKgel Alpha-M $7.8 \mathrm{~mm}$ ID $\times 30 \mathrm{~cm}, 13 \mu \mathrm{m} \rightarrow$ TSKgel Alpha-2500 $7.8 \mathrm{~mm} \mathrm{ID} \times 30 \mathrm{~cm}, 7 \mu \mathrm{m} \rightarrow$ TSKgel Alpha-2500 $7.8 \mathrm{~mm} \mathrm{ID} \times 30 \mathrm{~cm}, 7 \mu \mathrm{m})$. The column oven was held at $50^{\circ} \mathrm{C}$ during analysis. The mobile phase was DMF with $0.1 \mathrm{M} \mathrm{LiBr}$, the flow rate was $0.5 \mathrm{~mL}$ per min, and the oven temperature was $40^{\circ} \mathrm{C}$ on an injection volume of $10 \mu \mathrm{L}$. Molecular weight distributions were determined using Shimadzu GPC postrun software via a conventional calibration curve using a ReadyCal polystyrene Kit (Sigma-Aldrich, Aldrich \# 76552, M(p) 250-70000).

Saccharification assay. Saccharification was performed on $10 \mathrm{mg}$ of dried, ground stem material ${ }^{34}$. The samples were saccharified for $72 \mathrm{~h}$ using no pretreatment, acidic pretreatment $\left(1 \mathrm{M} \mathrm{HCl}, 80^{\circ} \mathrm{C}\right.$ for $2 \mathrm{~h}$ while shaking at $\left.750 \mathrm{rpm}\right)$, or alkaline pretreatment $\left(62.5 \mathrm{mM} \mathrm{NaOH}, 90^{\circ} \mathrm{C}\right.$ for $3 \mathrm{~h}$ while shaking at $\left.750 \mathrm{rpm}\right)$. After the pretreatment, the samples were centrifuged for $5 \mathrm{~min}$ at $10,080 \times \mathrm{g}$. The pellet was washed three times with $1 \mathrm{~mL}$ milliQ water, and incubated in $1 \mathrm{~mL}$ of $70 \%$ ethanol for $16 \mathrm{~h}$ at $55^{\circ} \mathrm{C}$. After another centrifugation step $(5 \mathrm{~min}$ at $10,080 \times g)$, the pellet was washed three times with $1 \mathrm{~mL} 70 \%$ ethanol and one time with $1 \mathrm{~mL}$ acetone, centrifuged for $5 \mathrm{~min}$ at $10,080 \times g, 10,000 \mathrm{rpm}$, dried under vacuum, and weighed.

The enzyme mix consisted of a 5:3 ratio of cellulase from Trichoderma resee $i$ ATCC 26921 and $\beta$-glucosidase (Novozyme) which were first desalted over an EconoPac 10DG column (Bio-Rad), stacked with Bio-gel ${ }^{\circledR}$ P-6DG gel (Bio-Rad) according to the manufacturer's guidelines. The activity of the enzyme mix was measured with a filter paper assay and was $0.18 \mathrm{FPU}$ (filter paper units) per $\mathrm{mL}$. Subsequently, the samples were dissolved in $1 \mathrm{~mL}$ acetic acid buffer solution $(\mathrm{pH}$ 4.8) and incubated at $50{ }^{\circ} \mathrm{C}$ at $750 \mathrm{rpm}$. After $5 \mathrm{~min}$ of incubation, $100 \mu \mathrm{L}$ freshly prepared enzyme mix was added. After spinning down the samples in a benchtop microcentrifuge, $20 \mu \mathrm{L}$ of the supernatant was taken after $72 \mathrm{~h}$ of incubation at $50^{\circ} \mathrm{C}$ and 30 -fold diluted with acetic acid buffer ( $\mathrm{pH} 4.8$ ). To determine the concentration of glucose in these samples, a spectrophotometric color reaction was used (glucose oxidase-peroxidase (GOD-POD); $100 \mathrm{~mL}$ of GOD-POD reaction

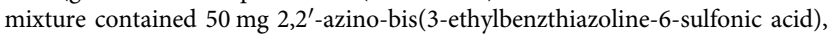
$44.83 \mathrm{mg}$ GOD, and $173 \mu \mathrm{L}$ POD (4\% (w/v)) in acetic acid buffer ( $\mathrm{pH} 4.5)$ ). To this end, $50 \mu \mathrm{L}$ of 30 -fold diluted sample was added to $150 \mu \mathrm{L}$ GOD-POD mixture and incubated for $30 \mathrm{~min}$ at $37^{\circ} \mathrm{C}$. The absorbance was measured spectrophotometrically at a wavelength of $405 \mathrm{~nm}$ (Microplate-reader SpectraMax 250 (Sopachem), SoftMax Pro version 5 was used for collecting data). The concentration in the original sample was calculated with a standard curve based on known D-glucose concentrations.

Phenolic profiling. For phenolic profiling, the frozen debarked stem parts were cut into little pieces using scissors. Subsequently, the stem pieces were extracted by adding $1 \mathrm{~mL}$ methanol and incubating for $15 \mathrm{~min}$ at $70^{\circ} \mathrm{C}$ while shaking at 1000 $\mathrm{rpm}$. After centrifugation at $19,757 \times \mathrm{g}, 800 \mu \mathrm{L}$ of the supernatant was transferred to a new Eppendorf and dried under vacuum. After dissolving the pellet in $100 \mu \mathrm{L}$ cyclohexane, $100 \mu \mathrm{L}$ milliQ water was added and the cyclohexane/water mixture was vortexed. After centrifugation at $19,757 \times g, 70 \mu \mathrm{L}$ of the water phase was subjected to UHPLC-MS on an ACQUITY UPLC I-Class system (Waters) consisting of a binary pump, a vacuum degasser, an autosampler, and a column oven. Chromatographic separation was performed on an ACQUITY UPLC BEH C18 $(150 \times 2.1 \mathrm{~mm}, 1.7 \mu \mathrm{m})$ column (Waters), while maintaining the temperature at $40^{\circ} \mathrm{C}$. A gradient of two buffers (A and B) was utilized: buffer A (99:1:0.1 water: acetonitrile:formic acid, $\mathrm{pH}$ 3) and buffer B (99:1:0.1 acetonitrile:water:formic acid, $\mathrm{pH}$ 3), as follows: $99 \%$ A for $0.1 \mathrm{~min}$ decreased to $50 \% \mathrm{~A}$ in $30 \mathrm{~min}$, decreased to $0 \%$ from 30 to $40 \mathrm{~min}$. The flow rate was $0.35 \mathrm{~mL}$ per min, and the injection volume was $10 \mu \mathrm{L}$. This UHPLC system was connected to a Vion IMS QTOF hybrid mass spectrometer (Waters). The LockSpray ion source was used in negative electrospray ionization mode under the following specific conditions: capillary voltage, $3 \mathrm{kV}$; reference capillary voltage, $2.5 \mathrm{kV}$; cone voltage, $30 \mathrm{~V}$; source offset, $50 \mathrm{~V}$; source temperature, $120^{\circ} \mathrm{C}$; desolvation gas temperature, $550^{\circ} \mathrm{C}$; desolvation gas flow, 800 liter per h; and cone gas flow, 50 liter per h. The collision energy for full MSe was set at $6 \mathrm{eV}$ (low energy) and ramped from 20 to $70 \mathrm{eV}$ (high energy), intelligent data capture intensity threshold was set at 5 . For DDA-MSMS, the low mass ramp was ramped between 15 and $30 \mathrm{eV}$. The high mass ramp was ramped between 30 and $70 \mathrm{eV}$. Nitrogen (greater than 99.5\%) was used as desolvation and cone gas. Leucin-enkephalin ( $250 \mathrm{pg}$ per $\mu \mathrm{L}$ solubilized in water:acetonitrile $1: 1(\mathrm{v} / \mathrm{v})$, with $0.1 \%$ formic acid) was utilized for the lock mass calibration, with scanning every $2 \mathrm{~min}$ at a scan time of $0.1 \mathrm{~s}$. Profile data were recorded through a UNIFI Scientific Information System (Waters). Data processing was performed with Progenesis QI software version 2.4 (Waters). All 30,662 peaks (mass-to-charge ratio $[\mathrm{m} / \mathrm{z}]$ features) were integrated in the chromatograms of wild type, CCR2(+I-), CCR2 $(-/+), \operatorname{CCR} 2\left(-I^{*}\right)$ line 12 , and CCR2 $(-/-)$. The 6182 peaks that had an abundance of at least $0.01 \%$ of the highest average in the group with the highest peak abundance were selected for further analysis. After ANOVA, peaks with a $P$ value $<0.01$ (false discovery rate adjusted) and a twofold difference in abundance between mutant and the wild type were considered as being significantly different. PCA and volcano plots were generated using MetaboAnalyst 4.0. Chemdraw 16 was used for calculating exact $\mathrm{m} / z$ values.
CCR2 activity assays in yeast. Malus domestica 4CL (Md4CL; GenBank Accession number XM_008365460) and yeast codon-optimized versions of the wild-type and mutant $P$. alba CCR2 alleles (Supplementary Fig. 15) were Gateway-cloned into the donor vector pDONR207 and sequence verified. For expression in yeast, the $M d 4 C L$ entry clone was Gateway-recombined into the high-copy number yeast destination vector pAG426GAL-ccdB (AddGene plasmid 1415535 $5^{35}$ ). The wild-type and mutant CCR2 alleles were also Gateway-recombined into the high-copy number yeast destination vector pAG424GAL-ccdB (AddGene plasmid $1415135^{35}$ ).

The resulting expression clones were used to transform yeast strain W303-1A (MATa; leu2-3,112, trp1-1, can1-100, ura3-1, ade2-1, his3-11,15) using the lithium acetate/single-stranded carrier DNA/polyethylene glycol method ${ }^{36}$. To this end, $50 \mathrm{~mL}$ YPD medium was inoculated with an overnight grown yeast pre-culture to an absorbance of 0.25 at $600 \mathrm{~nm}$. Subsequently, the culture was grown until the absorbance reached 1.0 by incubating at $30^{\circ} \mathrm{C}$. After harvesting the cells by centrifugation, the cells were washed with $1 \mathrm{~mL}$ lithium acetate $(0.1 \mathrm{M})$ and dissolved in $350 \mu \mathrm{L}$ lithium acetate $(0.1 \mathrm{M})$. For transformation, $50 \mu \mathrm{L}$-aliquots of the cells were transferred to an Eppendorf. To the aliquots, $200 \mu \mathrm{L}$ PLI solution (for $50 \mathrm{~mL}$ PLI solution, mix $40 \mathrm{~mL}$ of $50 \%$ PEG with $5 \mathrm{~mL}$ lithium acetate $(1 \mathrm{M})$ and $5 \mathrm{~mL}$ milliQ water), $10 \mu \mathrm{L}$ salmon sperm ssDNA and plasmid DNA ( $1 \mu \mathrm{g}$ of each plasmid) was added, followed by incubation for $30 \mathrm{~min}$ at $42^{\circ} \mathrm{C}$. After harvesting the cells by centrifugation, they were washed with $800 \mu \mathrm{L}$ milliQ water and plated on selective plates with synthetic-defined (SD) medium (Clontech) supplemented with -Trp/-Ura amino-acid dropout supplement (Clontech). After incubating the plates for 2 days at $30^{\circ} \mathrm{C}$, five independent transformed colonies were selected. In total, five independent biological cultures were made for strains containing (1) pAG426GAL-Md4CL + pAG424GAL-ccdB (empty vector control), (2) pAG426GAL-Md4CL + pAG424GAL-wild type_CCR2, and (3) pAG426GAL$M d 4 C L+$ pAG424GAL-mutant_CCR2.

Yeast precultures of each of the five biological replicates were grown in SD medium with -Trp/-Ura dropout supplement (Clontech) for $24 \mathrm{~h}$ at $30^{\circ} \mathrm{C}$ with shaking at $300 \mathrm{rpm}$. Gene expression was induced by washing the precultures with milliQ water and inoculating them in $10 \mathrm{~mL} \mathrm{SD} \mathrm{Gal/Raf} \mathrm{medium} \mathrm{with} \mathrm{-Trp/-Ura}$ dropout supplement. After incubating the cultures for $24 \mathrm{~h}, 500 \mu \mathrm{L}$ ferulic acid (20 $\mathrm{mM}$, in 50:50 ethanol:water) or $500 \mu \mathrm{L}$ coniferaldehyde $(20 \mathrm{mM}$, in $50: 50$ ethanol: water) was added. The cultures were incubated further for $48 \mathrm{~h}$. Finally, $1 \mathrm{~mL}$ of each yeast culture was harvested. After extracting the medium three times with 500 $\mu \mathrm{L}$ ethyl acetate, the solvent of the combined organic fractions was dried under vacuum. The remaining pellet was derivatized by using $10 \mu \mathrm{L}$ pyridine and $50 \mu \mathrm{L}$ $\mathrm{N}$-methyl- $\mathrm{N}$-trimethylsilyl-trifluoroacetamide (MSTFA) for GC-MS analysis on a GC model 6890 and MS model 5973 (Agilent Technologies). One microliter of the sample was injected in splitless mode with the injector port set to $280^{\circ} \mathrm{C}$ Separation was realized with a VF-5ms column $(30 \mathrm{~m} \times 0.25 \mathrm{~mm}, 0.25 \mu \mathrm{m}$; Varian CP9013; Agilent Technologies) with helium carrier gas at a constant flow of $1 \mathrm{~mL}$ per min. The oven was held at $80^{\circ} \mathrm{C}$ for 1 min post-injection, ramped to $280^{\circ} \mathrm{C}$ at $20^{\circ} \mathrm{C}$ per min, held at $280^{\circ} \mathrm{C}$ for $45 \mathrm{~min}$, ramped to $320^{\circ} \mathrm{C}$ at $20^{\circ} \mathrm{C}$ per min, held at $320^{\circ} \mathrm{C}$ for $1 \mathrm{~min}$, and finally cooled to $80^{\circ} \mathrm{C}$ at $50^{\circ} \mathrm{C}$ per min at the end of the run. The MSD transfer line was set to $250^{\circ} \mathrm{C}$ and the electron ionization energy was $70 \mathrm{eV}$. Full EI-MS spectra were recorded between $\mathrm{m} / \mathrm{z} 60$ and 800 with a solvent delay of $7.8 \mathrm{~min}$. GC-MS data were recorded and visualized with Agilent firmware and visualized via the AMDIS software (Version 2.6, NIST).

Statistical analyses. MS Excel 2016 and SAS 9.4 were used for statistical analysis The specific method used is mentioned in the respective Table and Figure legends.

Reporting summary. Further information on research design is available in the Nature Research Reporting Summary linked to this article.

\section{Data availability}

Data supporting the findings of this work are available within the paper and its Supplementary Information files. A reporting summary for this Article is available as a Supplementary Information file. The datasets generated and analyzed during the current study are available from the corresponding author upon request. Sequences data that support the findings of this study were obtained from the Aspen database (for the CCR2 sequences from $P$. tremula $\times$ P. alba; http://aspendb.uga.edu/) and NCBI (for the Malus domestica 4CL sequence; https://www.ncbi.nlm.nih.gov/nuccore/XM_008365460), or reported in Supplementary Information file. Source data are provided with this paper.

Received: 31 March 2020; Accepted: 16 September 2020; Published online: 06 October 2020

\section{References}

1. Vanholme, R., De Meester, B., Ralph, J. \& Boerjan, W. Lignin biosynthesis and its integration into metabolism. Curr. Opin. Biotechnol. 56, 230-239 (2019).

2. Mansfield, S. D., Kang, K.-Y. \& Chapple, C. Designed for deconstructionpoplar trees altered in cell wall lignification improve the efficacy of bioethanol production. N. Phytol. 194, 91-101 (2012). 
3. Van Acker, R. et al. Improved saccharification and ethanol yield from fieldgrown transgenic poplar deficient in cinnamoyl-CoA reductase. Proc. Natl Acad. Sci. USA 111, 845-850 (2014).

4. Voelker, S. L. et al. Antisense down-regulation of 4CL expression alters lignification, tree growth, and saccharification potential of field-grown poplar. Plant Physiol. 154, 874-886 (2010).

5. Leplé, J.-C. et al. Downregulation of cinnamoyl-coenzyme A reductase in poplar: multiple-level phenotyping reveals effects on cell wall polymer metabolism and structure. Plant Cell 19, 3669-3691 (2007).

6. Vanholme, R. et al. Caffeoyl shikimate esterase (CSE) is an enzyme in the lignin biosynthetic pathway in Arabidopsis. Science 341, 1103-1106 (2013).

7. De Meester, B. et al. Vessel-specific reintroduction of CINNAMOYL-COA REDUCTASE1 (CCR1) in dwarfed ccrl mutants restores vessel and xylary fiber integrity and increases biomass. Plant Physiol. 176, 611-633 (2018).

8. Muro-Villanueva, F., Mao, X. \& Chapple, C. Linking phenylpropanoid metabolism, lignin deposition, and plant growth inhibition. Curr. Opin. Biotechnol. 56, 202-208 (2019).

9. Pan, H. et al. Structural studies of cinnamoyl-CoA reductase and cinnamylalcohol dehydrogenase, key enzymes of monolignol biosynthesis. Plant Cell 26, 3709-3727 (2014).

10. Sonawane, P., Vishwakarma, R. K. \& Khan, B. M. Biochemical characterization of recombinant cinnamoyl CoA reductase 1 (Ll-CCRH1) from Leucaena leucocephala. Int. J. Biol. Macromol. 58, 154-159 (2013).

11. Chao, N. et al. Characterization of the cinnamoyl-CoA reductase (CCR) gene family in Populus tomentosa reveals the enzymatic active sites and evolution of CCR. Planta 245, 61-75 (2017)

12. Tsai, C.-J. \& Xue, L.-J. CRISPRing into the woods. GM Crops Food 6, 206-215 (2015).

13. Chabannes, M. et al. Strong decrease in lignin content without significant alteration of plant development is induced by simultaneous down-regulation of cinnamoyl CoA reductase (CCR) and cinnamyl alcohol dehydrogenase (CAD) in tobacco plants. Plant J. 28, 257-270 (2001).

14. Ralph, J. et al. Identification of the structure and origin of a thioacidolysis marker compound for ferulic acid incorporation into angiosperm lignins (and an indicator for cinnamoyl CoA reductase deficiency). Plant J. 53, 368-379 (2008).

15. Goujon, T. et al. Down-regulation of the AtCCR1 gene in Arabidopsis thaliana: effects on phenotype, lignins and cell wall degradability. Planta 217, 218-228 (2003).

16. Mir Derikvand, M. et al. Redirection of the phenylpropanoid pathway to feruloyl malate in Arabidopsis mutants deficient for cinnamoyl-CoA reductase 1. Planta 227, 943-956 (2008).

17. Kim, H. et al. Characterization and elimination of undesirable protein residues in plant cell wall materials for enhancing lignin analysis by solution-state nuclear magnetic resonance spectroscopy. Biomacromolecules 18, 4184-4195 (2017).

18. Van Acker, R. et al. Lignin biosynthesis perturbations affect secondary cell wall composition and saccharification yield in Arabidopsis thaliana. Biotechnol. Biofuels 6, 46 (2013).

19. Piquemal, J. et al. Down-regulation of cinnamoyl-CoA reductase induces significant changes of lignin profiles in transgenic tobacco plants. Plant J. 13, 71-83 (1998)

20. Chanoca, A., de Vries, L. \& Boerjan, W. Lignin engineering in forest trees. Front. Plant Sci. 10, 912 (2019).

21. Barrière, Y. Brown-midrib genes in maize and their efficiency in dairy cow feeding. Perspectives for breeding improved silage maize targeting gene modifications in the monolignol and p-hydroxycinnamate pathways. Maydica 62, 1-19 (2017).

22. Gui, J. et al. Fibre-specific regulation of lignin biosynthesis improves biomass quality in Populus. N. Phytol. 226, 1074-1087 (2020).

23. Zhou, X., Jacobs, T. B., Xue, L. J., Harding, S. A. \& Tsai, C. J. Exploiting SNPs for biallelic CRISPR mutations in the outcrossing woody perennial Populus reveals 4-coumarate:CoA ligase specificity and redundancy. N. Phytol. 208, 298-301 (2015).

24. Xue, L. J., Alabady, M. S., Mohebbi, M. \& Tsai, C. J. Exploiting genome variation to improve next-generation sequencing data analysis and genome editing efficiency in Populus tremula $\times$ alba 717-1B4. Tree Genet. Genomes 11, 82 (2015).

25. Jacobs, T. B. \& Martin, G. B. High-throughput CRISPR vector construction and characterization of DNA modifications by generation of Tomato hairy roots. J. Vis. Exp. 110, 53843 (2016).

26. Leplé, J. C., Brasileiro, A. C. M., Michel, M. F., Delmotte, F. \& Jouanin, L. Transgenic poplars: expression of chimeric genes using four different constructs. Plant Cell Rep. 11, 137-141 (1992).

27. Updegraff, D. M. Semimicro determination of cellulose in biological materials. Anal. Biochem. 32, 420-424 (1969).

28. Dence, C. W. in Methods in Lignin Chemistry, Vol. 33-61 (eds Lin, S. Y. \& Dence, C. W.) (Springer-Verlag, Berlin, Germany, 1992).
29. Van den Bosch, S. et al. Reductive lignocellulose fractionation into soluble lignin-derived phenolic monomers and dimers and processable carbohydrate pulps. Energy Environ. Sci. 8, 1748-1763 (2015).

30. Robinson, A. R. \& Mansfield, S. D. Rapid analysis of poplar lignin monomer composition by a streamlined thioacidolysis procedure and near-infrared reflectance-based prediction modeling. Plant J. 58, 706-714 (2009).

31. Kim, H. \& Ralph, J. Solution-state 2D NMR of ball-milled plant cell wall gels in DMSO-d6/pyridine-d5. Org. Biomolecular Chem. 8, 576-591 (2010).

32. Kim, H. et al. Solution-state $2 \mathrm{D}$ NMR of ball-milled plant cell wall gels in DMSO-d6. BioEnergy. Research 1, 56-66 (2008).

33. Mansfield, S. D. et al. Whole plant cell wall characterization using solutionstate 2D-NMR. Nat. Protoc. 7, 1579-1589 (2012).

34. Van Acker, R., Vanholme, R., Piens, K. \& Boerjan, W. Saccharification protocol for small-scale lignocellulosic biomass samples to test processing of cellulose into glucose. Bio-Protoc. 6, e1701 (2016).

35. Alberti, S., Gitler, A. D. \& Lindquist, S. A suite of Gateway ${ }^{\circledR}$ cloning vectors for high-throughput genetic analysis in Saccharomyces cerevisiae. Yeast 24, 913-919 (2007).

36. Gietz, R. D. \& Woods, R. A. Transformation of yeast by lithium acetate/single stranded carrier DNA/polyethylene glycol method. Methods Enzymol. 350, 87-96 (2002).

\section{Acknowledgements}

We thank Annick Bleys for help in preparing the article. B.D.M. is indebted to the Institute for the Promotion of Innovation through Science and Technology in Flanders (IWT-Vlaanderen) for a predoctoral fellowship and the Research Foundation Flanders (FWO) for a postdoctoral fellowship, B.M. was funded by the National Commission for Scientific and Technological Research (Chile) for a predoctoral fellowship, LdV was funded by IWT-Vlaanderen for a predoctoral fellowship. M.C. and J.R. were funded by the DOE Great Lakes Bioenergy Research Center (DOE Office of Science BER DESC0018409)

\section{Author contributions}

B.D.M., R.V., and W.B. designed the research; B.D.M., B.M., J.P., L.d.V., J.V.D., and M.C performed the experiments; B.D.M., B.M., J.P., L.d.V., and J.R. performed the data analysis; B.D.M., R.V., and W.B. wrote the article with contributions from all authors.

\section{Competing interests}

A patent application (WO2019234141A1) stating B.D.M., R.V., and W.B. as inventors on the use of plants having weak CCR alleles, resulting in lower lignin amounts and increased saccharification, has been filed jointly by VIB and Ghent University. All other authors declare no competing interests.

\section{Additional information}

Supplementary information is available for this paper at https://doi.org/10.1038/s41467$020-18822-w$

Correspondence and requests for materials should be addressed to W.B.

Peer review information Nature Communications thanks Laura Bartley, Jin-Gui Chen, Jenny Mortimer, and the other, anonymous, reviewer(s) for their contribution to the peer review of this work. Peer reviewer reports are available.

Reprints and permission information is available at http://www.nature.com/reprints

Publisher's note Springer Nature remains neutral with regard to jurisdictional claims in published maps and institutional affiliations.

Open Access This article is licensed under a Creative Commons Attribution 4.0 International License, which permits use, sharing, adaptation, distribution and reproduction in any medium or format, as long as you give appropriate credit to the original author(s) and the source, provide a link to the Creative Commons license, and indicate if changes were made. The images or other third party material in this article are included in the article's Creative Commons license, unless indicated otherwise in a credit line to the material. If material is not included in the article's Creative Commons license and your intended use is not permitted by statutory regulation or exceeds the permitted use, you will need to obtain permission directly from the copyright holder. To view a copy of this license, visit http://creativecommons.org/ licenses/by/4.0/

(C) The Author(s) 2020 